\title{
LA FAUNA RELACIONADA A UNA COMUNIDAD PREHISPÁNICA DEL PIEDEMONTE MERIDIONAL DE LA PROVINCIA DE TUCUMÁN (ARGENTINA)
}

\author{
Fauna related with a prehispanic population in Southern Piedmont of Tucuman \\ (Argentina)
}

Norma L. Nasif * y Gabriel E. Miguez*

\section{Resumen}

Este trabajo tiene como principal objetivo explorar, desde un enfoque amplio, diversos aspectos (económicos, simbólicos, entre otros) de las relaciones entre los animales y las comunidades prehispánicas del piedemonte meridional de la provincia de Tucumán, tomando como caso de estudio el sitio Yánimas 1 (ca. 1100-800 AP). Para tal fin, se realizó un análisis zooarqueológico de una muestra procedente de un montículo antropogénico de este sitio, utilizando parámetros taxonómicos, anatómicos, tafonómicos y contextuales, además de la consulta de fuentes etnográficas. Los resultados obtenidos permitieron reconocer una gran diversidad de animales aprovechados (entre silvestres y domésticos), que muestran un amplio patrón de distribución biogeográfica. Asimismo, a partir de la evaluación integrada de los datos se sugiere que parte de esta fauna tuvo una activa participación en prácticas rituales y ceremoniales, ya sea como parte de ofrendas, comidas o como objetos con poderes especiales.

$<$ Arqueofauna $><$ ocupaciones prehispánicas $><$ Noroeste Argentino $><$ piedemonte meridional $>$

\begin{abstract}
The main objective of this paper is to explore, from a comprehensive approach, different aspects (economic, symbolic, among others) of the relationships between animals and pre-Hispanic communities in the southern foothills of the Tucumán province, taking as a case study the Yánimas 1 site (ca. 1100-800 AP). Hence, a zooarchaeological analysis of a sample from an anthropogenic mound of this site was performed, using taxonomic, anatomical, taphonomic and contextual parameters, in addition to consultation of ethnographic sources. The obtained results allowed us to recognize a wide range of exploited taxa (including wild and domestic), showing a wide biogeographical distribution pattern. Also, the integrated data evaluation suggests that some of this wildlife had an active role in the practice of rituals and ceremonials, either as part of gifts, meals or as objects with special powers.
\end{abstract}

$<$ Archaeofauna $><$ prehispanic settlement $><$ Northwestern Argentina $><$ southern piedmont $>$

\footnotetext{
* Doctora en Ciencias Biológicas, Inst. Miguel Lillo - Facultad de Ciencias Naturales - UNT, norma_nasif@yahoo.com.ar

* Arqueólogo, Becario Doctoral SCyT/UNT, Inst. Miguel Lillo - Facultad de Ciencias Naturales - UNT, gabrielmiguez7@ hotmail.com
} 


\section{Introducción}

El área pedemontana meridional de la provincia de Tucumán es el espacio comprendido entre la Sierra del Aconquija (y sus estribaciones orientales) y la llanura tucumano-santiagueña. En sentido norte-sur, se extiende aproximadamente desde la localidad de Monteros hasta el límite interprovincial con Catamarca (Figura 1). Posee un rango altitudinal de 400 a $1000 \mathrm{msnm}$ y precipitaciones que promedian entre 800 y 2000 mm anuales (Sesma et al., 1998). Originalmente el área considerada estuvo dominada por formaciones selváticas (Selva Montana, entre 1000-700 msnm, y pedemontana, entre 700-400 msnm) componentes de la provincia fitogeográfica de las Yungas (Brown y Malizia, 2004). Hacia el oriente, en la zona de transición entre el piedemonte y la llanura tucumana, se forman ecotonos entre la selva pedemontana y la vegetación xerófila del bosque chaqueño semiárido, debido a la disminución de las precipitaciones (Pérez Miranda, 2003). Desde hace más de un siglo, esta vegetación viene siendo reemplazada por grandes extensiones de monocultivos, conservándose sólo algunos relictos de carácter secundario (Brown y Malizia, 2004). La fauna que se encontraba en estas selvas y bosques corresponde a la Región Biogeográfica Neotropical, provincias de las Yungas (Subregión Amazónica) y del Chaco (Subregión Chaqueña) (Morrone, 2002). La biota se desarrolla sobre un relieve ondulado con presencia de lomadas que caracterizan el paisaje pedemontano, el cual es atravesado por numerosos cursos fluviales que nacen en las serranías occidentales y se dirigen hacia el oriente hasta desembocar en el río Salí o en el dique frontal de Río Hondo (Miguez y Collantes, 2012).

Se conoce muy poco acerca de las comunidades que habitaron estas selvas en tiempos prehispánicos. Los trabajos previos son escasos y mayormente se han centrado en la caracterización de algunos sitios, fundamentalmente a partir de la somera descripción de materiales cerámicos ( $\mathrm{y}$, en menor medida, restos líticos) recuperados en intervenciones prospectivas, habiéndose realizado pocas excavaciones arqueológicas sistemáticas (Korstanje, 1992; Manasse, 1997; Rendace et al., 2006; Scattolin y Korstanje, 1994; Tartusi y Núñez Regueiro, 2003). En consecuencia, varios aspectos de las sociedades precoloniales pedemontanas son prácticamente desconocidos, como es el caso de las relaciones que pudieron haber desarrollado con la fauna de estos entornos. Sobre este tema, solo existen breves referencias a restos de animales hallados en algunos sitios precoloniales (Miguez, 2010; Rendace et al., 2006; Tartusi y Núñez Regueiro, 2003). Por ejemplo, Tartusi y Núñez Regueiro (2003: 52) citan el registro de huesos de un camélido en el sitio El Rincón (Dpto. La Cocha), que estarían asociados a un espacio residencial. Rendace et al. (2006) señalan que en excavaciones realizadas en el sitio Finca Elías 1 (Dpto. La Cocha) se recuperaron caracoles terrestres, espinas de peces, cáscaras de huevos y restos óseos de camélidos, entre otros vestigios orgánicos (junto con abundantes materiales cerámicos y líticos), vinculados con áreas de actividades domésticas, cerca de las cuales se rescataron urnas funerarias (Rendace et al., 2006: 830, 835). Por último, para el sitio Yánimas 1, cercano al anterior, Miguez (2010) menciona el registro de diversos vestigios arqueofaunísticos, entre los que destaca restos atribuibles a camélidos, placas de dasipódidos y cáscaras de huevos. 
La falta de estudios sobre las interacciones que las comunidades prehispánicas establecieron con la fauna que habitaba los bosques y selvas ubicados al oriente del Aconquija, no sólo limitó el conocimiento sobre el espectro de especies que pudieron haber aprovechado para su subsistencia, sino que también ha restringido las posibilidades de profundizar en otros aspectos que pudieron estar involucrados en estas relaciones. Nos referimos particularmente a aquellas actitudes y acciones que trascienden la mera cuestión económica para adentrarse en elámbito de lo socio-espiritual, las cuales pudieron haberse manifestado tanto en prácticas culturales como en otros ámbitos de la sociedad. En el registro arqueológico del Noroeste Argentino (NOA) este tipo de manifestaciones se encuentran expresadas en las representaciones zoomorfas o antropozoomorfas plasmadas en diversas tecnologías como la alfarería o el arte rupestre (i.e. Llamazares y Martínez Sarasola, 2004; González, 1977, 1998; Gordillo, 2009; Gudemos, 2003; entre otros), como también en los entierros humanos asociados con restos de fauna, o en inhumaciones de animales en montículos, viviendas o estructuras agrícolas, entre otros diversos contextos (López de Medina, 2012; Franco Salvi y Berberián, 2011; Gómez Cardozo et al., 2007; Salazar et al., 2011). Estos registros sugieren el desarrollo de una importante complejidad en las relaciones entre humanos y animales en aquellos tiempos pretéritos, que difícilmente puede abordarse con enfoques economistas o funcionalistas que solo se centren en la subsistencia o en las estrategias de obtención e intercambio. Sin embargo, la mayoría de los estudios zooarqueológicos suelen centrarse en la importancia económica que habría tenido la fauna registrada, reduciendo de esta manera las posibilidades interpretativas que pudieran realizarse sobre ella, como aquellas que refieren a los atributos sociales y sagrados que estas comunidades pudieron haberle asignado. Por el contrario, numerosos estudios etnográficos han demostrado que, en la cosmovisión de gran parte de las comunidades originarias americanas, la naturaleza no se entiende como separada de la cultura sino que es concebida como una esfera más del ámbito social y, por lo tanto, cargada de simbolismos y significados que dan sentido al universo que les rodea y a la vida misma, bajo concepciones de espacio-tiempo diferentes a las que caracterizan el pensamiento occidental moderno (Descola, 2001; Llamazares y Martínez Sarasola, 2004; entre otros). En pocas palabras, el mundo es comprendido como un todo ordenado según diferentes planos y espacios interconectados entre sí, dentro del cual el ser humano se encuentra co-habitando y compartiendo con diversas entidades (deidades míticas, seres tutelares, antepasados, dueños o señores de diversos ámbitos naturales o celestiales o de determinados seres animados o inanimados, entre otros, etc.), interaccionando con ellas de diversas formas y de manera continua (Califano y Dasso, 1999; Descola, 2001; Llamazares y Martínez Sarasola, 2004; Suarez, 2012). A estas entidades extra-físicas se suele atribuir comportamientos humanos y poderes especiales, y tienen su correspondencia con diversos elementos del entorno como cerros, ríos, plantas y más frecuentemente con animales, varios de los cuales son considerados sagrados (Llamazares y Martinez Sarasola, 2004). Con estos últimos, las comunidades originarias mantienen complejas interacciones que se han podido observar tanto en los ámbitos residenciales como fuera de ellos, ya sea en actividades de caza, pesca y recolección, en el caravaneo de llamas, y también en diversas prácticas rituales, entre 
otras actividades (Arenas, 2003; Califano, 1975; Califano y Dasso, 1999; Lecoq y Fidel, 2003; Miller, 1977; Ottalagano, 2007; Suárez, 2012; Vuotto, 1999).

Este trabajo pretende constituirse en un primer acercamiento a la relación humano-animal en el pasado prehispánico del piedemonte meridional tucumano, tomando como caso de estudio el sitio Yánimas 1. En tal sentido, se presentan los resultados de un análisis zooarqueológico llevado a cabo sobre una muestra del abundante material arqueofaunístico recuperado en este sitio, procedente de un montículo antropogénico (EM1). Teniendo en cuenta lo expresado en párrafos anteriores, a partir de la integración de varias líneas de evidencia (identificación taxonómica, observaciones tafonómicas, relaciones contextuales, consulta de fuentes etnográficas) pretendemos acercarnos a la complejidad de las posibles interacciones establecidas entre la comunidad que habitó este sitio y la fauna, explorando la diversidad de prácticas que pudieron estar involucradas (estrategias de movilidad y obtención de estos recursos, consumo, prácticas simbólicoreligiosas) y, asimismo, comprender la significación arqueológica de estos restos en el montículo EM1.

Figura 1. Ubicación del sitio Yánimas 1 y de otros sitios mencionados en el texto

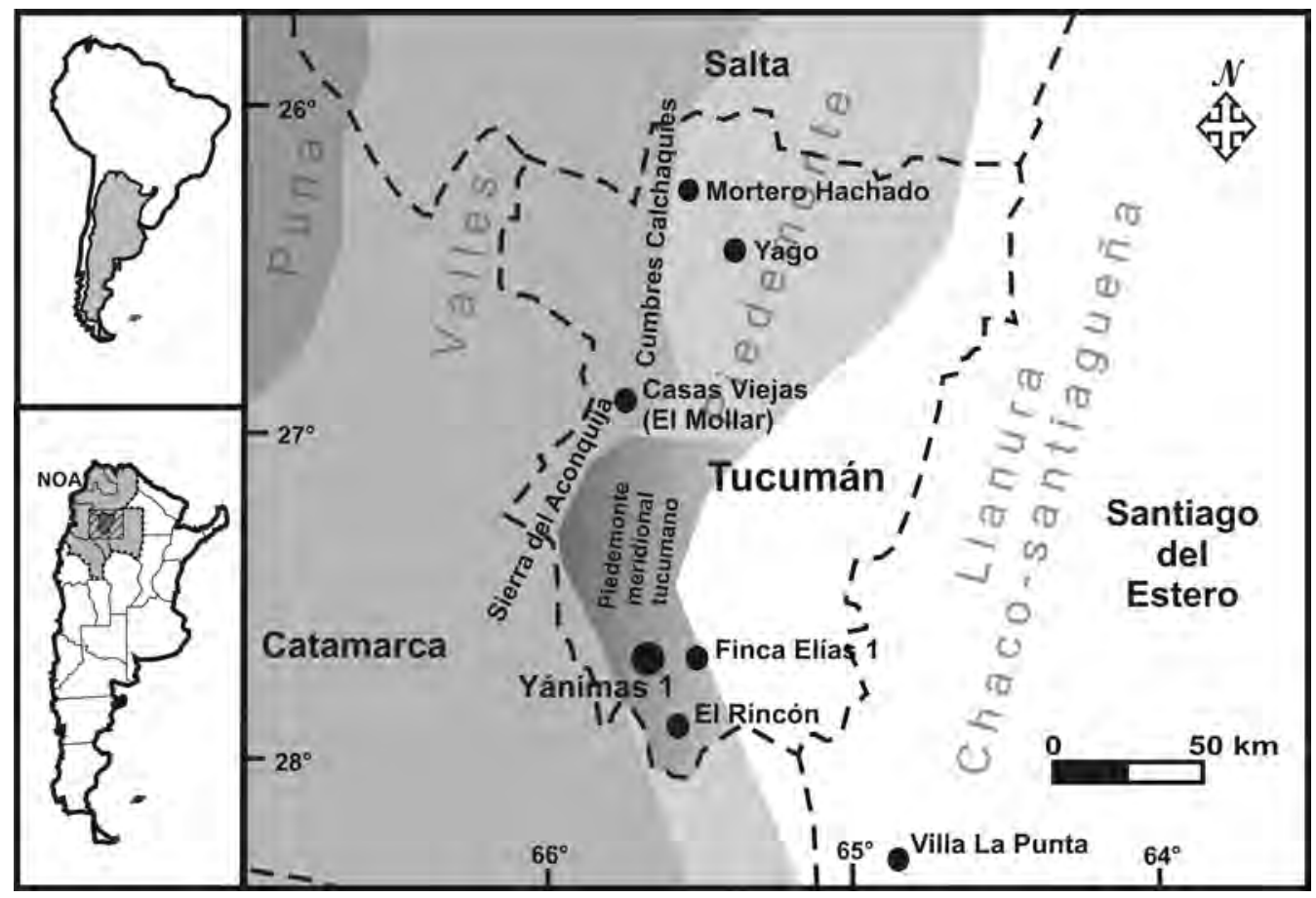

\section{El sitio Yánimas 1}

Este sitio se emplaza en la ribera meridional del río Marapa, extremo norte del departamento La Cocha, provincia de Tucumán(Figura1). Se caracteriza superficialmente por presentar en su Sector Central (SC), un conjunto de elevaciones monticulares (EM2, 
EM3 y EM4) de entre 120-150 m de longitud y una altura promedio de 1,5 m, que juntas conforman una $U$ abierta hacia el sur-suroeste. Estas elevaciones monticulares alargadas delimitan un espacio plano interior de alrededor de 1 ha. En una parte de la mitad oeste de EM2 se eleva otro montículo (EM1) de menor extensión. Alrededor del $\mathrm{SC}$ el sitio posee una superficie levemente ondulada donde se encuentran numerosos y variados restos distribuidos de manera regular sobre un área de gran extensión (40-50 ha) (Figura 2). A partir de los resultados obtenidos de las prospecciones y excavaciones, se ha propuesto para este sitio la existencia de diferentes espacialidades o lugares que habrían configurado una extensa y compleja ocupación prehispánica (Miguez et al., 2013).

Figura 2. Plano del sitio Yánimas 1

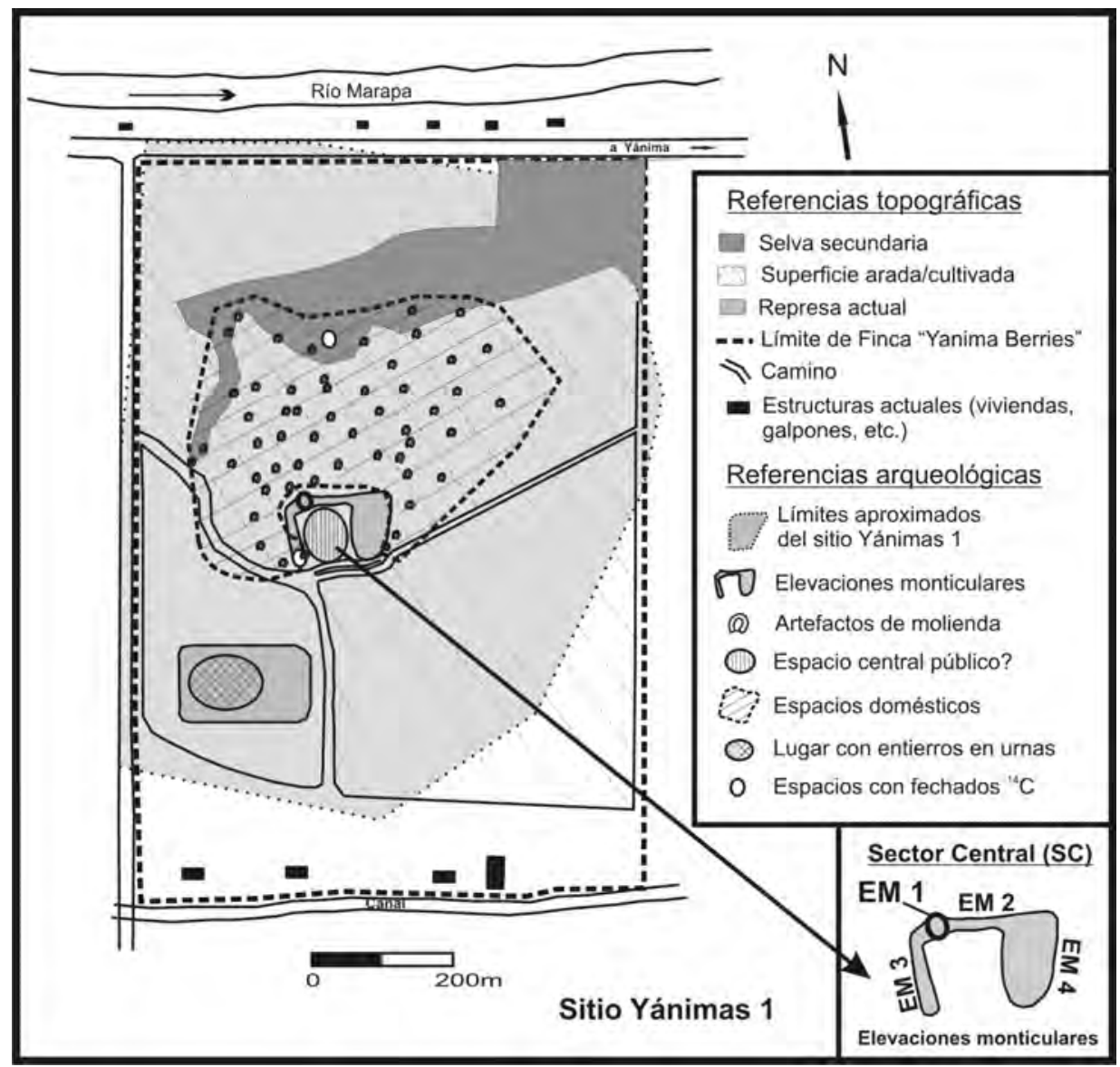

Los restos faunísticos analizados proceden del montículo EM1, el cual se distingue de las demás elevaciones monticulares tanto por su configuración externa como por su composición interna. Su altura de $3 \mathrm{~m}$ y su forma de cono truncado de base oval son características que le permiten destacarse en este paisaje. La excavación 
arqueológica en EM1 permitió recuperar gran cantidad y variedad de fragmentos cerámicos (incluyendo cuatro tubos de pipas), abundantes restos faunísticos y vegetales (carbón y carporrestos mayormente carbonizados), algunos materiales líticos tallados y pulidos, dos pequeñas láminas de oro, cuentas de collar, además de un diente humano y otros vestigios aún no determinados. Son recurrentes en su interior la presencia de concentraciones de sedimento de color blanquecino (de aspecto ceniciento), así como también de carbones de diferentes tamaños. Las determinaciones pedológicas efectuadas sobre muestras de sedimento muestran una variación irregular en los contenidos de materia orgánica $(\mathrm{MO})$ y fósforo $(\mathrm{P})$ a lo largo de la secuencia estratigráfica registrada en EM1. En línea con estos resultados, la frecuencia de materiales culturales (cerámica, lítico, restos orgánicos) recuperados por nivel excavado también presenta variaciones irregulares en la secuencia estratigráfica. Estos resultados, más la presencia de ciertos objetos en este contexto (i.e. láminas de oro, instrumento musical de hueso, entre otros) que son únicos en todo el sitio, así como las asociaciones de estos restos observadas en varios niveles, han llevado a proponer como hipótesis que la EM1 se habría formado por la sucesiva depositación de conjuntos de materiales culturales (y tal vez, también de sedimentos) en eventos no cotidianos, posiblemente relacionados con prácticas rituales (Miguez et al., 2012; Miguez et al., 2013).

Un espacio muy cercano a la EM1 es una estructura monticular de tierra (con varias rocas en su interior que se disponen de forma más o menos ordenada) ubicada en el extremo oeste de la EM2. Su construcción implicó el movimiento de grandes volúmenes de tierra. En su parte superior presenta dos alineamientos de piedras que delimitan un espacio alargado y estrecho a modo de pasillo que, en cuanto a la circulación, vincula espacialmente este lugar con la EM1 (Miguez et al., 2013). Otro lugar importante es el extenso espacio llano y deprimido que se halla delimitado por las estructuras monticulares alargadas. Posee un escaso registro arqueológico tanto en superficie como en estratigrafía. Posiblemente constituyó un amplio lugar de carácter público, abierto a la circulación e interacción entre los agentes, y donde también pudieron haberse desarrollado diversas actividades comunitarias, algunas de las cuales pudieron estar relacionadas con los ritos y ceremonias cuyos restos formaron EM1. Por último, otros lugares intervenidos podrían interpretarse como ámbitos residenciales donde se desenvolvieron múltiples actividades, tales como el extremo sur de la EM3 y otros espacios ubicados en los alrededores del SC (Miguez et al., 2013).

La ocupación descripta ha sido ubicada cronológicamente, de acuerdo con dos fechados radiocarbónicos (Tabla 1), entre fines del primer milenio y los primeros siglos del segundo después de Cristo (ca. 1100-800 AP). Cabe destacar que este rango temporal es congruente con la presencia de ciertos materiales cerámicos que poseen atributos formales y decorativos comparables con los estilos Ambato Negro Grabado y Ambato Tricolor. Si bien no son los únicos estilos cerámicos registrados en Yánimas 1 , sí se encuentran entre los más frecuentes y están presentes en varios de los espacios intervenidos durante las tareas de campo, como en los contextos fechados y en el montículo EM1, asociados a restos arqueofaunísticos y otros tipos de materiales. Esta 
alfarería posee una fuerte presencia en ocupaciones prehispánicas de los valles orientales de la provincia de Catamarca (Cruz, 2006; González, 1998; Gordillo, 2009; Laguens, 2004; entre otros) y el piedemonte meridional de Tucumán (Manasse, 1997; Miguez et al., 2013; Tartusi y Núñez Regueiro, 2003) y tradicionalmente se la ha vinculado a ocupaciones de la segunda mitad del primer milenio d.C. Sin embargo, recientes estudios basados en el análisis de series de fechados radiocarbónicos existentes para el Ambato y zonas aledañas, extienden este rango cronológico hasta los primeros siglos del segundo milenio d.C. (Gordillo, 2007), coincidiendo con los fechados de Yánimas 1.

Tabla 1. Fechados radiocarbónicos del sitio Yánimas 1

\begin{tabular}{|c|c|c|c|c|c|}
\hline Lab/Código & Material & Procedencia & $\begin{array}{l}\text { Edad }{ }^{14} \mathrm{C} \\
\text { (años AP) }\end{array}$ & $\begin{array}{c}\text { Edad Calib.* } \\
(\mathrm{dC}) \pm 1 \sigma\end{array}$ & $\begin{array}{l}\text { Edad Calib. }^{*} \\
\text { (dC) } \pm 2 \sigma\end{array}$ \\
\hline $\begin{array}{l}\text { LATYR - } \\
2185\end{array}$ & $\begin{array}{l}\text { Hueso } \\
\text { humano }\end{array}$ & $\begin{array}{l}\text { Sector Norte - } \\
\text { Entierro } 1 \text { - Prof.: } \\
90-100 \mathrm{~cm} .\end{array}$ & $960 \pm 70$ & $1042-1182$ & $1014-1231$ \\
\hline $\begin{array}{l}\text { LATYR - } \\
2403\end{array}$ & $\begin{array}{c}\text { Hueso de } \\
\text { Lama glama }\end{array}$ & $\begin{array}{c}\text { Sector Central - } \\
\text { porción meridional } \\
\text { de EM3 - Prof.: } \\
20-40 \mathrm{~cm} .\end{array}$ & $1060 \pm 60$ & $984-1048$ & $936-1160$ \\
\hline
\end{tabular}

\section{Metodología}

La intervención arqueológica llevada a cabo desde la cima del montículo EM1 comprendió cinco unidades de $1 \mathrm{x} 1 \mathrm{~m}$ (unidades $1,2,4,6,8$ ) dispuestas en forma de cruz, las cuales fueron excavadas siguiendo niveles artificiales de $10 \mathrm{~cm}$, hasta una profundidad máxima de $130 \mathrm{~cm}$ (unidad 1). La muestra analizada corresponde al registro arqueofaunístico de las unidades 2 y 4 . Esta muestra se constituye de materiales de variada naturaleza e incluyen huesos completos y fragmentados, además de cáscaras de huevos, caracoles, entre otros restos. Este registro fue analizado desde los puntos de vista anatómico y taxonómico mediante la identificación macroscópica de atributos morfológicos, medidas osteológicas, colecciones de referencia y bibliografía especializada (Olrog y Lucero, 1981; Pacheco-Torres et al., 1986; Mengoni Goñalons, 1988; Bárquez et al., 1991; Olrog, 1995; Ortíz et al., 2012; Izeta et al., 2009; entre otros).

Para la identificación específica de los restos de camélidos, se siguió el criterio osteométrico de la primera falange, considerando medidas estandarizadas: el largo máximo (Lm); el ancho máximo de la superficie articular proximal (BFp) y distal (BFd) y la profundidad máxima de las epífisis proximal (Dp) y distal (Dd) (Izeta et al., 
2009; Cartagena Fasting, 2009); también se observaron rasgos anatómicos diferenciales presentes en algunos huesos del esqueleto apendicular (Adaro y Benavente, 1990). Las medidas fueron tomadas con calibre manual metálico de tipo Vernier. El número de falanges medibles (con epífisis fusionadas a las diáfisis) en la muestra analizada es reducido (una falange proximal y dos falanges mediales), por lo que no se realizaron estudios estadísticos y los valores obtenidos se muestran en los resultados. Las edades de camélidos y otros grupos de mamíferos se estimaron mediante el criterio de estado de emergencia/desgaste dentario y fusión de las epífisis (Kent, 1982; Puig y Monge, 1983; Mengoni Goñalons, 1999; Kaufmann, 2009). Sobre la base de la metodología aplicada por Mengoni Goñalons (1999) se distinguieron dos categorías de estados de fusión respecto de las epífisis: huesos no-fusionados y huesos fusionados, lo que da una idea aproximada de la edad inmadura o madura osteológicamente (respectivamente) de muerte de los animales.

Para la determinación taxonómica de un bezoar (cálculo formado en los intestinos de grandes mamíferos) además de la observación macroscópica de sus caracteres formales y dimensiones, también se sometió el objeto a un análisis químico mediante Difractometría de Rayos-X por el Método de Polvo, realizados en laboratorios (IDGYM e IESGLO) de las Universidades Nacionales de Jujuy y Tucumán. La identificación específica de las cáscaras de huevos de Rheidae se realizó siguiendo el criterio de Apolinaire y Turnes (2010), basado en la determinación de la densidad de los poros superficiales. En tal sentido se efectuó el conteo de poros en áreas de $1 \mathrm{~cm}^{2}$, a través de fotografías digitales.

A fin de evaluar sus representatividades relativas respecto del total de la muestra identificada, se realizó la cuantificación de los especímenes determinados por taxón (NISP y NISP\%). Los especímenes correspondientes a fragmentos de piel, cáscaras de huevos y astillas de huesos menores de $1 \mathrm{~cm}$, así como los fragmentos de caracoles, no se contabilizan a fin de no sobrevalorar la abundancia relativa de los taxa. Además se aporta información acerca de características biológicas, etológicas y biogeográficas de los taxa determinados (Bárquez et al., 1991; Ortíz et al., 2012; entre otros) con el objeto de discutir aspectos relacionados con procesos de alteración que pudieron haber ocurrido en EM1 producto de las conductas propias de algunos animales, y también para aproximarnos a las probables estrategias utilizadas por agentes humanos para la obtención (movilidad, técnicas de caza, etc.) y consumo de estos recursos. Para enriquecer la discusión se incluye información sobre algunos restos faunísticos identificados en otros contextos del sitio.

Los procesos tafonómicos observados en los restos óseos, como las alteraciones provocadas por procesos naturales (meteorización, carroñeo, pisoteo, impregnaciones químicas) o las producidas por acciones antrópicas (fracturas y marcas intencionales, termoalteraciones, formatizaciones) han sido identificadas siguiendo los lineamientos propuestos por determinados especialistas (Beherensmeyer, 1978; Binford, 1981; Lyman, 1994; Mengoni Goñalons, 1988, 1999). 
Para profundizar en cuestiones relacionadas al consumo, funcionalidad y/o significación simbólica de ciertos restos identificados, hemos consultado fuentes etnográficas y arqueológicas que refieren principalmente a comunidades originarias del norte argentino (Noroeste y Chaco). Finalmente, la arqueofauna motivo de este trabajo es evaluada desde el punto de vista contextual, mediante parámetros cuantitativos (frecuencias por nivel) (Figura 3) y cualitativos (asociaciones registradas). Los resultados de estos análisis (tafonómico y contextual) nos permitirán discutir las posibles prácticas en las que pudieron haber participado los restos de animales registrados en EM1 y las formas en que pudieron contribuir a la formación del montículo.

\section{Resultados}

Se logró la identificación taxonómica del total de los especímenes óseos que conforman la muestra (NISP $=625$ ). Los resultados indican una alta diversidad de animales, que abarcan todas las clases de vertebrados, correspondiendo a mamíferos, aves, reptiles, anfibios y peces (Tabla 2). En el registro también se reconocen restos de invertebrados consistentes en múltiples fragmentos de conchillas y algunas completas de moluscos (Gasterópoda) terrestres, que corresponderían a tres taxa, así como un nido de insecto de barro, que se encuentra quemado. Estos restos no fueron contabilizados en el NISP porque todavía se encuentran en proceso de análisis, y porque el alto grado de fragmentación de las conchillas sobreestimaría su representatividad en la muestra. Respecto del total de restos óseos identificados: 1) la clase mayoritaria es la de mamíferos $(91,36 \%)$, entre los cuales los Artiodactyla son el orden mejor representado (61,92\%), incluyendo cérvidos (Cervidae) y camélidos (Camelidae), así como los restos no identificables asignados a artiodáctilos grandes y chicos; 2) los Rodentia (12,16\%) constituyen el segundo escalón en importancia cuantitativa e incluyen chinchillones y vizcachas (Chinchillidae), coipo (Myocastoridae), ocultos (Ctenomyidae), cuises (Caviidae), pericotes (Cricetidae) y roedores de diferente porte cuyos restos son no identificables a un menor nivel sistemático; 3) luego le siguen los Xenarthra (4,16 $\%$ ), representados por quirquinchos (Dasypodidae) y 4) los Carnivora (Felidae) (0,16 $\%$ ). También se contabilizan los restos mal preservados que sólo pueden atribuirse a mamíferos medianos y chicos (12,96\%). En cuanto a los restos óseos de aves, si bien su proporción en la muestra es escasa $(0,96 \%)$, se reconocen varios taxa tales como Rheiformes, Accipitriformes, Passeriformes y aves medianas no identificadas. Cabe aclarar que también se han identificado gran cantidad de fragmentos de cáscaras de huevos correspondientes a Rhea americana, que no fueron contabilizados. Entre los restos de reptiles $(3,52 \%)$ se determinaron ejemplares del Orden Squamata (ofidios y lagartos chicos y grandes), mientras que los anfibios $(2,08 \%)$ están representados por los Anura de tamaño chico y grande. Por último, se registran restos de peces $(2,08 \%)$ correspondientes a los órdenes Siluriformes y Characiformes. 
Nasif y Miguez. La fauna relacionada a una comunidad prehispánica...

Tabla 2. Diversidad faunística y Abundancia Taxonómica (NISP) del Montículo Mayor (EM1) del sitio Yánimas 1, Unidades 2 y 4. NISP, números de especímenes identificados por taxón

\begin{tabular}{|c|c|c|}
\hline & TAXÓN/CATEGORÍA & NISP \\
\hline \multicolumn{3}{|l|}{ PECES } \\
\hline & Siluriformes indet. & 11 \\
\hline & Caraciformes indet. & 2 \\
\hline \multicolumn{3}{|l|}{ ANFIBIOS } \\
\hline & Anura indet. (ch) & 12 \\
\hline & Cerathophrys sp. & 1 \\
\hline \multicolumn{3}{|l|}{ REPTILES } \\
\hline & Teiidae indet. (ch) & 8 \\
\hline & Teiidae indet. (g) & 9 \\
\hline & Tupinambis sp. & 2 \\
\hline & Squamata indet. & 3 \\
\hline \multicolumn{3}{|l|}{ AVES } \\
\hline & Ave indet. (m) & 3 \\
\hline & Passeriformes indet. & 1 \\
\hline & Falconidae indet. & 1 \\
\hline & Rhea americana & 1 \\
\hline \multicolumn{3}{|c|}{ MAMÍFEROS } \\
\hline & Rodentia indet. (ch) & 50 \\
\hline & Rodentia indet.(m) & 8 \\
\hline & Rodentia indet. (g) & 4 \\
\hline & Sigmodontinae indet. & 1 \\
\hline & Chinchillidae indet. & 1 \\
\hline & Graomys centralis & 2 \\
\hline & Ctenomys sp. & 4 \\
\hline & Lagidium viscascia & 2 \\
\hline & Lagostomus maximus & 2 \\
\hline & Myocastor coipus & 1 \\
\hline & Galea sp. & 1 \\
\hline & Dasypodidae indet. & 8 \\
\hline & Chaetophractus vellerosus & 18 \\
\hline & Felidae indet. & 1 \\
\hline & Artiodactyla indet. (g) & 108 \\
\hline & Artiodactyla indet. (ch) & 6 \\
\hline & Mazama sp. & 18 \\
\hline & Hippocamelus antisensis & 24 \\
\hline & Camelidae indet. & 69 \\
\hline & Lama glama & 7 \\
\hline & Mamífero indet. (g) & 155 \\
\hline & Mamífero indet. (m) & 65 \\
\hline & Mamífero indet. (ch) & 16 \\
\hline & TOTAL & 625 \\
\hline
\end{tabular}


El análisis de las alteraciones producidas por agentes naturales permite evaluar la integridad de la muestra (sensu Binford, 1981). En tal sentido, solo el 4,8\% de la misma presenta indicios de alteración debida a procesos meteóricos, ubicando la muestra entre los estadios 0-2 (sin descascarado o fisuras hasta con exfoliación y agrietamiento superficial) de Beherensmeyer (1978), lo que implica una baja meteorización previa a la depositación. Se observó una proporción muy baja $(0,64 \%)$ de restos con marcas atribuibles a la acción de carnívoros (tipo pozos semicirculares en superficie y muescas en los bordes) en cuatro fragmentos óseos, correspondientes al cráneo de un quirquincho, al astrágalo de un camélido, a la cabeza del fémur de un mamífero grande y la vértebra lumbar de un artiodáctilo juvenil. Por otra parte, se atribuyen a roedores $(0,16 \%)$ las marcas cortas y paralelas (Mengoni Goñalons, 1999) distribuidas en los márgenes de una lámina de costilla de un artiodáctilo grande. Además, se distinguen huesos con indicios de aplastamiento que podrían haberse provocado por presión sedimentaria o por pisoteo, aunque su determinación precisa requiere de un estudio más detallado. En particular, hay indicios de adherencias posiblemente calcáreas (en dos huesos) y daños de corrosión (posiblemente ocurridos en un contexto sedimentario húmedo) en un conjunto de huesos correspondientes al extremo distal apendicular y a una vértebra de un taruca (niveles 3 y 4 en unidad 2), los cuales se encuentran aún bajo análisis.

Respecto a las huellas de acciones humanas sobre estos restos, se reconocieron fracturas longitudinales y transversales para extracción de médula, con huellas de impacto en forma de muesca o escotadura semicircular (Mengoni Goñalons, 1999), en un $1,28 \%$ de los restos, correspondiendo a fragmentos de metapodios, diáfisis y falanges de artiodáctilos grandes. Los vestigios termoalterados representan un 11,84\% del total de restos identificados. Algunos están quemados (coloración marrón/rojiza), carbonizados (coloración negra) y otros calcinados (coloración gris/azulada a blanco). Se manifiestan principalmente en placas de dasipódidos (Figura $4 \mathrm{LL}$ ), fragmentos tipo astillas de diáfisis, un sesamoideo y una patela de artiodáctilos (sin huellas de procesamiento), así como en huesos largos de roedores y en algunos fragmentos de cáscaras de huevos (además del nido de insecto). Estos restos están presentes en cantidades muy variables (desde 1 hasta un máximo de 20) en los niveles de excavación 3-6 (30-60 cm) en la unidad 4 y en todos los niveles de la unidad $2(10-80 \mathrm{~cm})$. Así, los restos alterados térmicamente de la muestra analizada presentan alto estado de fragmentación, grado variable de termoalteración, ausencia de marcas de procesamiento observables a nivel macroscópico, irregularidad en su distribución y cantidad en el perfil analizado. Este patrón puede vincularse a prácticas humanas no necesariamente vinculadas al consumo, sino al descarte, desecho, depositación intencional de huesos en lugares de combustión o aledaños o su empleo como material de combustión (Mengoni Goñalons, 1999). En esta muestra se reconoció un hueso formatizado (ave rapaz, instrumento musical) (Figura 4 J) procedente del nivel $4(30-40 \mathrm{~cm})$ de la unidad 4, este instrumento presenta múltiples y variadas marcas producidas en su tecnofactura y uso. Este aerófono fue motivo de un estudio interdisciplinario muy detallado, cuyos resultados fueron expuestos en otro trabajo (Miguez et al., 2013). Cabe resaltar que no es el único hueso formatizado registrado para el montículo EM1, ya que en el nivel $13(120-130 \mathrm{~cm}$.) de la unidad $1 \mathrm{se}$ 
encontró una posible punta ahuecada (Buc, com. pers., 2014), confeccionada en hueso de artiodáctilo (Figura $4 \mathrm{~K}$ ).

En relación al contexto de procedencia, la contabilización de los restos arqueofaunísticos por nivel en ambas unidades (2 y 4), muestra una serie de aumentos y disminuciones en las frecuencias que se alternan de manera irregular (Figura 3). Lo mismo ocurre con otras materialidades como la cerámica y los macrorrestos vegetales (Miguez et al., 2012). Por otra parte, durante el proceso de excavación se han registrado en varios niveles distintas asociaciones concretas de materiales (fragmentos de vasijas, pipas, materiales líticos, carporrestos carbonizados y otros objetos) a las que también se encuentran estrechamente vinculados los restos óseos (en algunos casos articulados, como patas de ciervos y vértebras de ofidios), las cáscaras de huevos y/o conchillas de gasterópodos. Muchas veces estas asociaciones estaban relacionadas espacialmente con manchas de sedimento fino, blanquecino (ceniza) y carbones de diferentes tamaños.

Figura 3. Frecuencia de restos óseos de fauna por nivel excavado en las unidades 2 y 4 de EM1

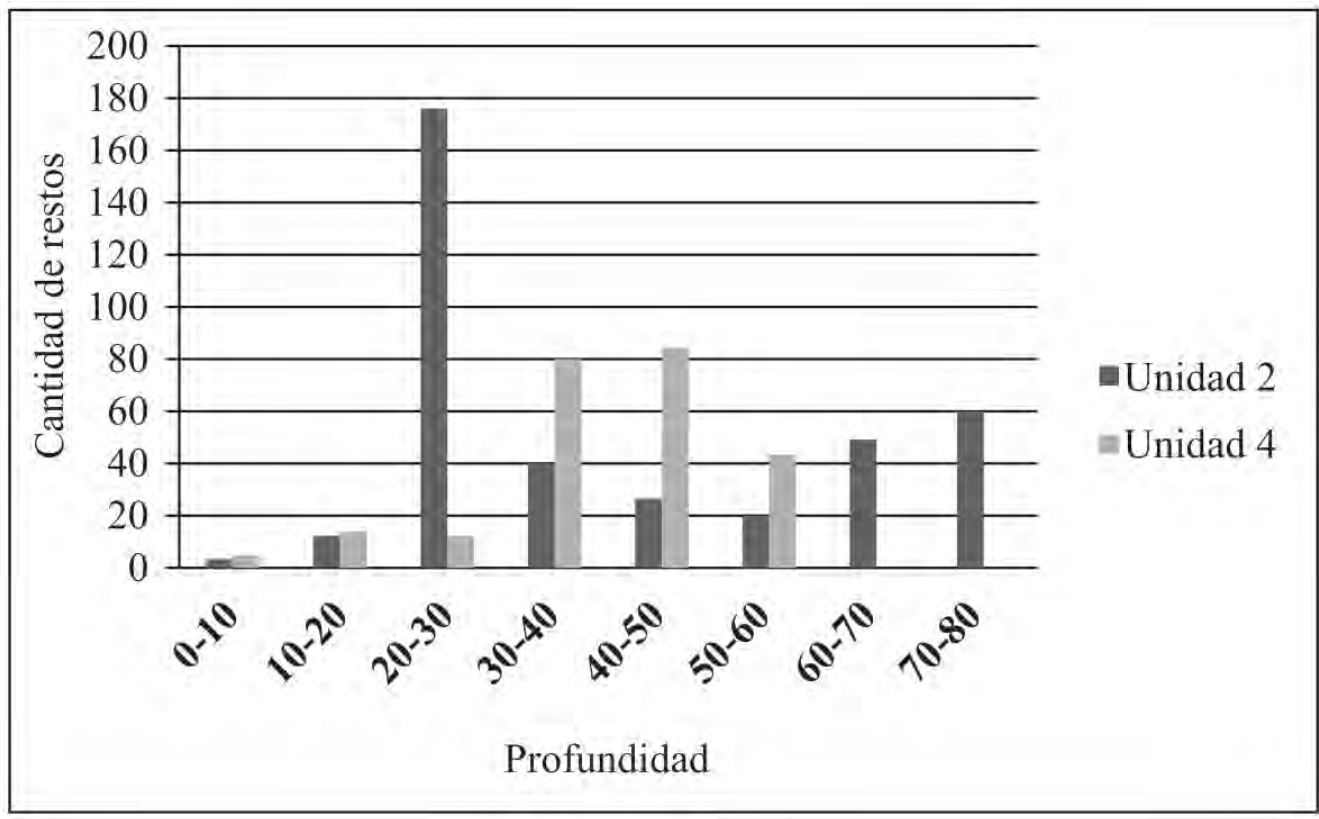

A continuación se amplían los resultados de los análisis taxonómicos, anatómicos, tafonómicos y contextuales obtenidos para cada taxón. Asimismo se aporta información sobre hábitos y biogeografía de los grupos de animales identificados. Por último, se agregan datos de fuentes arqueológicas y etnográficas. La integración de estos datos nos permitirá evaluar las prácticas y significaciones que pudieron haber tenido estos animales en el contexto social de Yánimas 1. 


\section{Mamíferos}

Los camélidos constituyen el $12,16 \%$ respecto del total de especímenes identificados y un 48,71\% del conjunto de los artiodáctilos. Sus restos se hallaron en toda la estratigrafía del montículo. Predominan los huesos apendiculares: fragmentos de metapodios, diáfisis, epífisis de fémures y radio/ulnas, huesos centrales y falanges (primeras, segundas y ungueales, algunas completas) (Figura 4 A-C); aunque también se registran muy pocos fragmentos de costillas y vértebras. Los resultados de la medición de tamaños (en mm) correspondientes a una falange proximal (F1: Lm 68,0; BFp 21,0; Dp 19,0; BFd 17,0 y Dd 17,0) y a dos falanges mediales (F2: Lm 35,0; BFp 17,5 y 18,3 ; Dp 15,0 y 16,8; BFd 16,0 y 14,4 y Dd 13,0 y 14,2) de individuos adultos, comparados con medidas de falanges actuales y arqueológicas (Izeta et al., 2009), permiten sugerir de manera muy preliminar, dado la reducida cantidad de elementos medibles, la presencia de Lama glama (llama) en este conjunto. Además, se refiere a este taxón un resto de radio/ulna que presenta su epífisis proximal equidimensional y la tuberosidad olecraneana roma en el extremo articular proximal de la ulna, dado que estos rasgos (entre otros más de huesos apendiculares) son característicos del morfotipo llama entre las especies de camélidos sudamericanos (Adaro y Benavente, 1990). Cabe destacar también que, en otra parte del sitio (porción meridional de la EM3) se registran varias primeras falanges cuyos tamaños entran en el rango de esta especie doméstica de camélidos. Sin embargo, la alta variabilidad intrapoblacional existente en la morfología esquelética de los camélidos condiciona la diferenciación interespecífica haciendo necesario un estudio comparativo más amplio para contrastar estos primeros resultados.

En los huesos de camélidos procedentes de EM1, se determinó la presencia de diferentes edades ontogenéticas, tanto adultos (con epífisis fusionadas) $(n=18)$ como juveniles (con epífisis parcialmente fusionadas, sin epífisis fusionadas o epífisis naturalmente aisladas) $(n=14)$, correspondiendo a metapodios, falanges y en menor proporción a fémur, vértebras y fragmentos de cráneo. Además, el reconocimiento de huellas de acciones humanas (fracturas por impacto y huesos quemados) en parte de los restos (metapodios, falanges y costillas), como también el registro de marcas de corte en algunos huesos de camélidos provenientes de EM3 (asignados a Lama glama), constituyen indicios que podrían estar indicando su aprovechamiento para consumo.

Diversos trabajos realizados en contextos etnográficos y arqueológicos demuestran la importancia que ha tenido la llama no solo en relación al consumo y el tráfico e intercambio de bienes materiales e inmateriales mediante el caravaneo, sino también en su participación de determinadas prácticas rituales vinculadas a la fertilidad, el culto a los antepasados y otras cuestiones simbólicas (Miller, 1977; Franco Salvi y Berberián, 2011; Lecoq y Fidel, 2003; entre otros). Otro elemento asignado a camélido es un bezoar o "piedra bezoar", objeto semicircular de estructura concéntrica y superficie lisa de 1,6 x 1,3 x 0,9 mm (Figura 4 D). Los resultados del análisis de Difractometría de Rayos-X identifican en su composición un fosfato anhidro de calcio (Whitlockita $[\beta$ $\mathrm{Ca} 3(\mathrm{PO} 4) 2]$ ), sustancia que caracteriza a este tipo de estructuras y permite corroborar su asignación taxonómica. Los bezoares de camélidos han sido muy valorados en el mundo 
andino, tanto en tiempos coloniales como pre-coloniales (y todavía en la actualidad), por las propiedades curativas físicas y mentales (alivia dolores estomacales, mejora la digestión, contrarresta los efectos de venenos, cura el miedo, la melancolía y las pasiones del corazón, entre otros) que les eran atribuidas (Browman, 2004; Loza, 2007). Se trata de un material escaso en los registros arqueológicos y su presencia puede ser evidencia de la práctica de sacrificios de camélidos para su obtención (Afanador Llach, 2011).

Los cérvidos constituyen un $8.48 \%$ respecto del total de especímenes identificados y un $33,97 \%$ del conjunto de los artiodáctilos. Entre estos restos Hippocamelus antisensis (taruca) es el taxón mejor representado ( $\mathrm{n}=24)$ (Tabla 2). Se trata de un ciervo de porte grande que habita en los ambientes abiertos de pastizales de neblina de las Yungas y estepas rocosas del noroeste argentino (NOA), a alturas comprendidas entre los 3.000 a 5.000 msnm (Olrog y Lucero, 1981; Bárquez et al., 1991; Díaz, 1995). Según Loza (2007: 332) el taruca es un animal sagrado en la cosmovisión de algunos grupos andinos $\mathrm{y}$, entre otros atributos, es utilizado en rituales curativos contra, por ejemplo, el "mal viento" que causa la parálisis facial. En menor proporción se reconocieron restos de Mazama sp. (corzuela) ( $\mathrm{n}=18)$, y además hay fragmentos de huesos largos asignados a artiodáctilos chicos (no juveniles, $\mathrm{n}=6$ ) que pueden corresponder a este último taxón (ver Tabla 2). En la provincia de Tucumán se distribuyen dos especies del género Mazama, M. americana y M. gouazoubira, la primera habitan los bosques y selvas de las Yungas mientras que la segunda especie se distribuye más al este de la provincia y habita preferentemente en el área chaqueña (Bárquez et al., 1991). La corzuela es y ha sido un animal frecuentemente cazado y consumido por comunidades originarias del Chaco, con un aprovechamiento integral del mismo (Arenas, 2003; Dasso, 2008).

A nivel anatómico, en los restos correspondientes a ambos taxa de cérvidos, predominan huesos del extremo distal de las patas, metapodios $(\mathrm{n}=15)$ y falanges $(\mathrm{n}=19)$. Cabe destacar que al menos dos patas de taruca articuladas fueron halladas en estratigrafía (nivel 3 de la unidad 2; nivel 4 de la unidad 8; Figura 4 F-G), asociados a otros restos tales como grandes fragmentos cerámicos, cáscaras de huevos, lascas, piedras, y restos de otros animales, entre otros. La extremidad hallada en la unidad 2 incluye falanges, sesamoideos, huesos centrales y fragmentos de metapodios que presentan fracturas intencionales por impacto. En el caso de la corzuela, los restos que corresponden a los extremos distales de extremidades han sido hallados en forma no articulada o aisladas. Un dato interesante es la presencia de falanges ungueales, ya que en ciertos grupos mataco del norte argentino se ha observado el uso de sonajeros compuestos por pezuñas de corzuela, particularmente en danzas rituales de iniciación chamánica (Califano, 1975). Por último, también están presentes dientes aislados (premolares y un molar) de este animal (Figura 4 E).

Los armadillos o quirquinchos (Dasypodidae) están representados mayormente por osteodermos de la coraza dorsal (fijos y movibles), aislados (Figura 4 LL). Por la ornamentación de los osteodermos se identifica en el conjunto a Chaetophractus vellerosus, especie que en Tucumán y el noroeste argentino se encuentra ampliamente 
distribuido en zonas de altura, en áreas boscosas y de monte chaqueño (Bárquez et al., 1991). Además, se asigna a esta especie un fragmento de maxilar con dientes. Hay otros osteodermos de tamaño y ornamentación diferentes que dan cuenta de la presencia de otra especie de dasipódidos en el registro, aún no identificada. Buena parte de los osteodermos tienen diversos grados de termoalteración (quemados y calcinados), lo que podría estar evidenciando su aprovechamiento con fines alimenticios o su presencia en cercanías de unidades de combustión por conductas de desecho o descarte. Esta especie ha sido identificada en otros sitios del piedemonte tucumano (Caria et al., 2011). Actualmente, varios grupos chaqueños cazan (a garrotazos) y consumen esta y otras especies de quirquinchos, con frecuencia asados al rescoldo y con el caparazón (Arenas, 2003; Dasso, 2008), lo que puede explicar la presencia de estas placas termoalteradas.

Los carnívoros solamente están representados por un único hueso completo, un metapodio atribuible a un félido (Felis sp.) (Figura 4 L). Por su tamaño y morfología podría corresponder a un gato de porte chico. Un rasgo notable observado en el hueso es la textura serosa y adherencias sedimentarias que posee en su superficie. Este tipo de huellas pueden vincularse a procesos de cocción, previos a la depositación (Mengoni Goñalons, 1988), si bien hacen falta análisis químicos de estos residuos para corroborar esta interpretación. Existen varias especies de félidos chicos que habitan el área de estudio o zonas cercanas (Felis colocolo, Felis geoffroyi, Felis yagouaroundi) (Bárquez et al., 1991). En el sitio Mortero Hachado (Dpto. Trancas), ubicado en la porción septentrional del piedemonte tucumano, se ha identificado también un solo resto óseo correspondiente a un félido chico (Nasif et al., 2007). De acuerdo con la cronología estimada para este sitio (primeros siglos del segundo milenio d.C.), su ocupación pudo haber sido contemporánea con Yánimas 1. En general, varios felinos (grandes y pequeños) son cazados y consumidos por diversos grupos del Chaco sudamericano (Arenas, 2003; Dasso, 2008), si bien en algunos casos existen tabúes alimentarios y otras cuestiones que hacen que su consumo sea restringido (Arenas, 2003). Esto concuerda con la baja frecuencia de estos animales en los registros arqueológicos pedemontanos y de gran parte del NOA. Por otra parte, es importante recordar que el felino se encuentra representado iconográficamente en numerosos y variados materiales procedentes de diversos contextos arqueológicos del NOA. En este sentido, Yánimas 1 no es la excepción, ya que las figuras felínicas también están presentes en parte de la alfarería decorada, particularmente en la iconografía de la cerámica negra pulida y grabada. Si bien dicha iconografía es tradicionalmente vinculada al jaguar (Panthera onca), podemos pensar que estas figuras tal vez refieran también a otros felinos como los registrados en la muestra arqueofaunística.

Los restos de roedores son frecuentes en este montículo y se identificaron varias especies correspondientes a las Familias Cricetidae, Caviidae, Ctenomyidae y Chinchillidae. Los cricétidos (pericotes y lauchas), de porte pequeño, están mayormente representados por huesos largos de adultos yjuveniles. Todos se encuentran desarticulados, una gran parte presentan signos de termoalteración (quemados, carbonizados o calcinados) y se ubican en el nivel de excavación más profundo $(70-80 \mathrm{~cm})$. Estos indicios, sumado 
a que no se evidenciaron cuevas en el perfil del sitio, permiten plantear la procedencia arqueológica de estos roedores pequeños. En este conjunto hay tres hemimandíbulas con dentición correspondientes al sigmodontino Graomys centralis. Otros roedores de porte chico corresponden a ctenómidos (Ctenomys sp., tucu-tuco) (Figura 4 N) y cávidos (Galea sp., cuis). Están representados por mandíbulas y un maxilar, respectivamente, con molares preservados. Además se registran varios fragmentos de piel, que por la coloración (gris pardusco), largo y grosor del pelaje podrían atribuirse a cuises. Los ocultos son netamente cavadores y edificadores de galerías y túneles, y los cuises se refugian en cuevas o cavan en suelos blandos. Si bien hay varios indicios en estos restos que permitirían apoyar su procedencia arqueológica (termoalteración en los restos, su hallazgo en los niveles más profundos de la excavación) no se puede descartar que su integración en este registro se deba a procesos postdeposicionales. Cabe mencionar que los ocultos y cuises son frecuentemente hallados en contextos arqueológicos del NOA, y en algunos casos se ha considerado su participación en la alimentación (Nasif et al., 2007). Además, los cuises se han identificado en modelados de cerámica en un montículo que ha sido considerado como un espacio sagrado, ubicado en el sitio Casas Viejas (valle de Tafí, Tucumán) (Gómez Cardozo et al., 2007; Nasif y Gómez Cardozo, 2007).

Los roedores medianos a grandes identificados son los chinchíllidos: Lagidium viscascia (chinchillón) (Figura 4 O) y Lagostomus maximus (vizcacha). El chinchillón se distribuye a lo largo de las cadenas montañosas del oeste de Argentina. En Tucumán habita en las altas montañas, principalmente en zonas rocosas y secas, tiene actividad diurna y vive en grupos familiares. La vizcacha se distribuye ampliamente en la región chaqueña y en Tucumán habita principalmente áreas ubicadas al este y norte del sitio en estudio (Bárquez et al., 1991). Los restos de chinchillón en EM1 consisten en dos mandíbulas con dentición y las vizcachas están representadas por un fémur completo (a partir de varios fragmentos remontados) y un fragmento de cúbito calcinado y con una marca de impacto, lo cual podría indicar que este último taxón fue utilizado como recurso alimenticio. Los chinchíllidos constituyen uno de los grupos de vertebrados de mayor importancia arqueológica, ya que fueron utilizados por las poblaciones humanas como recurso alimenticio y materia prima (Elkin y Rosenfeld, 2001; Nasif y Gómez Cardozo, 2007; Quintana y Mazzanti, 2011). Esta tendencia también ha sido registrada en diversos contextos etnográficos (Arenas, 2003; Dasso, 2008). Cabe señalar que estos roedores son difíciles de distinguir a partir de restos fragmentarios siendo, por lo general, identificados en la literatura zooarqueológica solo a nivel de familia (Elkin y Rosenfeld, 2001; Nasif y Gómez Cardozo, 2007). La identificación de Lagidium entre los restos analizados de EM1 se efectuó a partir del reconocimiento de caracteres mandibulares y dentarios (Ortíz et al., 2012).

También se ha identificado un resto óseo de Myocastor coypus (coipo o falsa nutria), una hemimandíbula con dentición correspondiente a un ejemplar juvenil (presenta el premolar deciduo, el primer molar con desgaste, el segundo en proceso de emergencia y el tercero aún sin indicios de eclosión) (Figura 4 M). El coipo es un 
animal semiacuático, con habilidades para nadar, habita zonas inundadas, esteros y lagunas, forman grupos coloniales y en Tucumán tienen una distribución restringida al centro norte de la provincia (Bárquez et al., 1991). La incorporación de un único resto perteneciente a un ejemplar juvenil de este taxón, y sin indicios de procesamiento podría estar indicando que su incorporación al registro arqueológico pudo ser a través de prácticas relacionadas con aspectos simbólicos. Por lo general, las evidencias arqueológicas del uso del coipo como recurso alimenticio están basadas en el registro de numerosos ejemplares subadultos y adultos, ya que los mismos presentan mayor masa corporal y, por ende, mayor rinde económico (Santini, 2011; Sartori y Colasurdo, 2012; Escosteguy et al., 2012).

\section{Figura 4. Componentes del registro arqueofaunístico del EM1 del Sitio Yánimas 1}

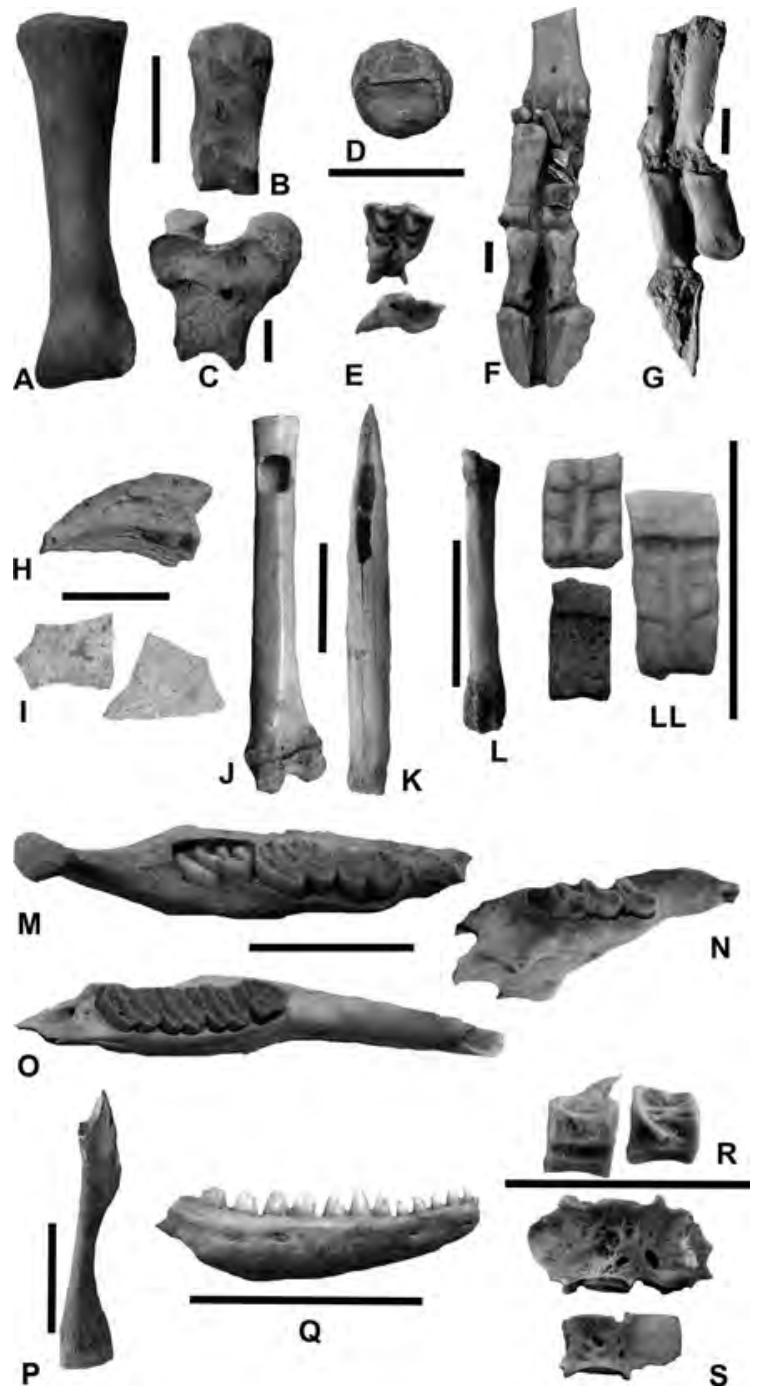

A, primera falange de Lama glama;

$\mathrm{B}$, segunda falange de Camelidae;

C, epífisis distal de fémur de Camelidae juvenil;

D, piedra bezoar de Camelidae;

E, premolar y molar de Mazama sp.;

F-G, patas (extremo distal) de

Hippocamelus antisensis, cuyos elementos óseos (metapodio y falanges) están en posición articulada tal como fueron hallados en el sitio;

H-I, falange ungueal de Rhea americana;

I, fragmentos de cáscaras de huevos de Rhea americana;

$\mathrm{J}$, fémur de Falconidae formatizado en un instrumento musical del tipo silbato;

$\mathrm{K}$, hemiparte de metapodio de Artiodactyla formatizado en un instrumento de tipo punta ahuecada;

L, metapodio de Felidae;

LL, osteodermos fijos y movibles de Chaetophractus vellerosus, uno de ellos con signos de termoalteración;

$\mathrm{M}$, hemimandíbula con dientes de un individuo juvenil de Myocastor coipus;

$\mathrm{N}$, hemimandíbula con dientes de Ctenomys sp.;

$\mathrm{O}$, hemimandíbula con dientes de Lagidium vizcachia;

$\mathrm{P}$, húmero de Ceratophrys sp.;

Q, porción anterior de hemimandíbula con dentición de Tupinambis sp.;

$\mathrm{R}$, vértebras de Characiformes;

$\mathrm{S}$, vértebras de Siluriformes. 
La avifauna registrada es escasa y corresponde a aves de tamaño pequeño (metatarso de Passeriforme), mediano (no identificadas) y grandes (Tabla 1). Entre las de mayor porte se reconoce a Rhea americana (ñandú) a través de una falange ungueal y de gran cantidad de fragmentos de cáscaras de huevos (Figura $4 \mathrm{H}-\mathrm{I}$ ), algunos con signos de termoalteración, lo que podría indicar su procesamiento para consumo. Cabe acotar que los resultados preliminares del análisis de densidad de poros superficiales de los fragmentos de cáscaras entran en el rango establecido para Rhea americana (mayor al $80 \%$ promedio por $\mathrm{cm}^{2}$ ) (Apolinaire y Turnes, 2010). Los restos de ñandú más comunes en sitios prehispánicos del norte argentino (NOA y NEA) son las cáscaras de sus huevos, mientras que los restos óseos son bastante más escasos en el registro arqueológico. En tal sentido, tal vez el hallazgo de un resto óseo puede estar implicando el consumo cárnico de este animal. Sin embargo, su depositación en este montículo pudo haber tenido otra significación. El ñandú es otro de los animales profusamente representado en soportes tales como las vasijas cerámicas (estilos Aguada y Santamariano) durante épocas prehispánicas, por lo que se presupone que en aquellos tiempos debió haber tenido una fuerte importancia simbólica, ya que, por ejemplo, se lo encuentra pintado en varios ejemplares de las conocidas urnas funerarias santamarianas, así como también en algunos estilos que forman parte del repertorio cerámico Aguada (ver González, 1977: 325, 331, 1998; Gómez Augier y Caria, 2009: 101). Según Gómez Augier y Caria (2009: 101) en la cosmovisión de las comunidades originarias de los valles áridos del NOA, el ñandú ha sido -e incluso lo es actualmente- uno de los animales tradicionalmente vinculado a fenómenos climáticos como la lluvia, situación que puede deberse al comportamiento del animal en momentos previos a las precipitaciones. Estos autores señalan también que es recurrente el hallazgo de cáscaras de huevos de suri en urnas funerarias del período Tardío, los cuales habrían sido depositados como ofrenda (Gómez Augier y Caria, 2009).En grupos nativos del Chaco (como los wichí y los toba), además de constituir una importante fuente de alimento en el pasado (Arenas, 2003), el ñandú también ha tenido gran relevancia desde el punto de vista simbólico, a tal punto que sus plumas fueron utilizadas para adornar sus cuerpos en varios tipos de rituales, como los de iniciación chamánica (Califano, 1975; Ottalagano, 2007).

También se identifica la Familia Falconidae que agrupa aves rapaces (halcones, chimangos y caranchos) a través de un fémur formatizado, constituyendo un instrumento musical del tipo flauta con el extremo inferior cerrado (silbato) (Figura $4 \mathrm{~J}$ ). El hueso sólo carece de la epífisis proximal por un corte realizado intencionalmente para obtener el área de embocadura y entrada de aire de este aerófono. La diáfisis y la epífisis distal están completas, preservándose en ellas rasgos anatómicos característicos de los falcónidos (Miguez et al., 2013). La Familia Falconidae está ampliamente distribuida en Argentina. Este objeto fue hallado a la misma profundidad $(40-50 \mathrm{~cm})$ y relativamente cercano a dos tubos de pipas, en un nivel inmediatamente inferior a una de las láminas de oro registradas en este montículo (Miguez et al., 2013; Miguez, 2014). Dicho instrumento es muy similar a los silbatos chaqueños de hueso registrados en contextos 
etnográficos del norte argentino (Pérez Bugallo, 1989). Su uso está vinculado con prácticas rituales chamánicas inducidas por enteógenos (Califano, 1975; Pérez Bugallo, 1989). Cruz (2006) ha mencionado el hallazgo de dos silbatos del mismo tipo en el Recinto Alto del sitio Piedras Blancas (Valle de Ambato, Catamarca). Destaca que se han registrado en un mismo nivel de ocupación, donde también se encontraron tres sepulturas de niños, ofrendas de animales, estructuras de combustión y otros objetos de fuerte carácter simbólico, evidencias que estarían reflejando el desarrollo de actividades rituales (Cruz, 2006: 135). La presencia de estos delicados instrumentos musicales, entre otros registrados en la arqueología del NOA (Miguez et al., 2013), sumado al importante repertorio de imágenes que aluden a diferentes especies de aves (suris, cóndores, lechuzas, patos, etc.) manifestados en diversos estilos cerámicos del NOA (Sunchituyoj, Averías, Aguada, Candelaria, Santamaría, entre otros) y NEA (por ejemplo, en la tradición cerámica de los ribereños plásticos) nos hablan de la gran relevancia que han tenido estos animales en la cosmovisión de diversos grupos prehispánicos (cfr. González, 1977, 1998). Esta relevancia también ha sido puesta de manifiesto en diversas fuentes etnográficas, etnohistóricas y folklóricas referidas a comunidades originarias del norte de nuestro país, que muestran a estos animales representados en diversas creencias y relatos míticos, y expresados en diferentes ceremonias y rituales (Gómez Augier y Caria, 2009; Ottalagano, 2007). En tal sentido, resulta interesante la estrecha relación que suele darse entre los chamanes y las aves, particularmente en sesiones de vuelos o viajes espirituales que aquellos experimentan mediante el trance extático. En estos vuelos, el alma del chamán trasciende la envoltura corporal y se traslada a otros mundos con diversos objetivos, para lo cual durante el viaje suele transformarse en varios animales, especialmente en ciertas aves voladoras como colibríes, búhos y caranchos (Llamazares y Martínez Sarasola, 2004; Ottalagano, 2007: 219). Según Llamazares y Sarasola (2004: 67) los chamanes aprenden de ellas no solo a volar, sino también el poder de la visión, de captar visualmente otras realidades.

\section{Reptiles}

Entre los reptiles se identifican los Teiidae (lagartos) a través de huesos del cráneo y apendiculares completos. En el conjunto hay al menos un taxón de lagartos de porte chico y otro de porte grande (Tupinambis sp.). Entre los huesos de Tupinambis se reconocen dos fragmentos de mandíbulas con dientes (Figura 4 Q) de diferentes tamaños por lo que corresponden a dos individuos, el ílion y una vértebra sacra completa (Montero et al., 2004). Tupinambis tiene hábitos cavícolas y esta conducta podría implicar su incorporación al registro como agente perturbador (Salemme et al., 2012), sin embargo sus restos se ubican en los niveles más profundos de excavación, donde no se registran cuevas o túneles. Este lagarto habita en el área de estudio, tanto en ambientes de selva pedemontana como en los ecotonos ubicados entre estas selvas y el bosque chaqueño. Según registros etnográficos, grupos del Chaco salteño no solo consumen su carne y huevos, sino que también aprovechan el cuero y la grasa, esta 
última para uso medicinal (Arenas, 2003; Dasso, 2008), lo que permite entrever que su relevancia en la vida y cosmovisión de estas comunidades.

También se registran vértebras de ofidios (culebras y/o serpientes) de al menos dos taxa diferentes por su tamaño y según las comparaciones con colecciones de referencia podrían corresponder a culebras. El ofidio de tamaño mayor está representado por dos vértebras y el de tamaño menor por numerosas vertebras $(\mathrm{n}=20)$ de similar morfología (dos de ellas están articuladas) y fueron halladas en un mismo sector y nivel de excavación, esto permite interpretar que corresponden a un mismo individuo (en Tabla 1 se contabiliza como un ejemplar).

Cabe mencionar que no se observan en los huesos de reptiles signos de termoalteración o procesamiento, por lo que no puede indicarse su posible consumo, además por lo general cuando esto ocurre las evidencias óseas son muy numerosas (Salemme et al., 2012), lo cual no es el caso del registro en estudio. Estos datos permiten sugerir la depositación de individuos enteros de lagartos grandes y ofidios en el EM1. Los ofidios han sido profusamente representados en diversos estilos cerámicos desarrollados en tiempos prehispánicos en el NOA (e.g., Aguada, Santamariano, entre otros), por lo cual debió haber tenido un importante papel en la vida y cosmovisión de muchas comunidades de este pasado. Como dato más cercano, en un sector periférico al sitio, se rescató una urna funeraria tapada con un puco estilo Averías. Interesa resaltar que el cuello de la urna (de cerámica tosca y superficie cepillada), está decorado con la posible representación de un ofidio, aplicado al pastillaje.

\section{Anfibios}

Los anfibios identificados son al menos dos taxones de anuros, uno de tamaño chico (apófisis transversa de vértebra y fragmentos de huesos largos) $(\mathrm{n}=12)$ y uno grande. Este último corresponde a un fémur casi completo de Cerathophrys sp. (escuerzo) (Figura 4 P, Tabla 2). Varios huesos de anfibios de menor porte tienen signos de termoalteración. Estos animales han sido frecuentemente representados en estilos cerámicos arqueológicos como Candelaria (modelados) y Santamaria (pintados), característicos de la porción centro-norte del piedemonte tucumano y áreas aledañas. Precisamente, en el sitio Yago, ubicado al norte de esta provincia (cuenca Tapia-Trancas), también se han identificado extremidades de anuros (Caria et al., 2011). Son animales muy frecuentes en la simbología prehispánica e histórica del NOA, particularmente asociados a fenómenos climáticos (Gómez Augier y Caria, 2009).

\section{Peces}

En el registro analizado hay numerosas vértebras de peces que corresponden en su totalidad a Characiformes (bogas) y Siluriformes (bagres o viejas del agua) (Figura 4 R-S; ver NISP en Tabla 2). Los bagres viven al fondo de los cuerpos de agua, no forman cardúmenes, pero a veces, algunas especies de bagres, siguen los cardúmenes de Characiformes durante las migraciones. Este tipo de conductas podría haber influido en la obtención simultanea de estos dos taxa de peces. La presencia de vértebras de peces 
podría estar indicando su consumo cárnico. Este es el segundo registro de peces en el área de estudio. Como ya ha sido señalado, en el sitio Finca Elías 1 se encontraron restos de peces en estratigrafía, principalmente espinas (Rendace et al., 2006).

\section{Discusión y consideraciones finales}

De acuerdo a los resultados de este estudio la fauna registrada en el EM1 de Yánimas 1 es muy diversa, incluyendo animales de porte grande (camélidos, cérvidos y rheidos) y otros más pequeños (roedores, armadillos, reptiles, anfibios, peces y moluscos terrestres), que mayormente corresponden a fauna silvestre. Con excepción de ciertos roedores pequeños y los invertebrados, se interpreta que la mayoría de estos taxa constituyeron recursos aprovechados para diversos fines por la comunidad que habitó este sitio entre fines del primer milenio d.C. e inicios del segundo. Asimismo, la identificación preliminar de Lama glama (llama) en este registro arqueofaunístico nos lleva a proponer el uso complementario entre animales silvestres y, posiblemente, domésticos. Los animales silvestres habrían sido obtenidos de diferentes hábitats y ecorregiones, mediante prácticas de caza, trampeo, pesca, posiblemente recolección, e incluso a través de prácticas de intercambio con otras poblaciones. Esto implicaría una alta movilidad en las estrategias utilizadas para la obtención de estos recursos, con trayectorias que implicaron diferentes direcciones y distancias: hacia el oeste, en las cumbres de serranías altas habrían cazado tarucas y chinchillones; en ambientes selváticos y ecotonos cercanos pudieron cazar corzuelas, ñandúes, quirquinchos, lagartos como los tupinambis, así como también peces en cursos de agua próximos (ríos Marapa y Medina); en zonas más secas dominadas por el Bosque Chaqueño, roedores grandes como la vizcacha, armadillos y también ñandúes, entre otros.

Los artiodáctilos de porte grande (camélidos y cérvidos) son los mayoritariamente representados en el registro analizado. La predominancia de huesos de los miembros anteriores y posteriores (falanges y metapodios) puede dar cuenta de una selección de partes para las actividades llevadas a cabo en este sector del sitio. Las marcas de impacto en algunos de los huesos largos indicarían su procesamiento para obtención de médula ósea. Por otra parte, la abundancia de cérvidos registrada es apenas menor a la de los camélidos, y de ambos taxones hay varios individuos (adultos y juveniles), lo que permite sugerir que ambos grupos de artiodáctilos tuvieron un rol importante en la subsistencia del grupo humano.

En el caso de Lama glama y camélidos en general, el reconocimiento de varias partes anatómicas, así como también de huellas de acción humana (fracturas, marcas de corte y termoalteraciones) y la identificación de individuos de diferentes edades sugieren que estos animales han sido aprovechados de manera integral para su consumo (carne y médula). Cabe mencionar que esta especie ha sido identificada en otras ocupaciones prehispánicas del piedemonte septentrional de Tucumán en la cuenca Tapia-Trancas, tales como Yago (en el primer milenio d.C.) y Mortero Hachado (en el segundo milenio d.C.), sitios para los que se plantea tanto el consumo como la cría de llamas (Nasif et al., 2007; Caria et al., 2011). 
Resulta interesante también que para estas ocupaciones prehispánicas de la cuenca Tapia-Trancas se lista un espectro taxonómico de la fauna relativamente comparable a Yánimas 1. Estas tendencias nos permiten sugerir, por un lado, que las poblaciones pedemontanas llevaban a cabo el aprovechamiento de una amplia gama de recursos faunísticos silvestres y que además se ha utilizado a la llama como recurso doméstico, al menos desde mediados del primer milenio d.C. hasta los siglos iniciales del segundo. Esto muestra una diferencia con, por ejemplo, ocupaciones ubicadas en la llanura santiagueña (por ejemplo, Villa La Punta, cronológicamente ubicado a mediados del primer milenio d.C., y El Veinte, cuyos fechados lo ubican entre ca. 1000-1200 d.C.), en las que, si bien se registra también una amplia diversidad de taxones (Cione et al., 1979; del Papa, 2010), aún no se ha determinado la presencia de restos de animales domésticos (e.g. llama). También se observan importantes diferencias entre el material arqueofaunístico analizado y el procedente de sitios ubicados en valles occidentales aledaños, como el valle de Ambato (Catamarca), donde varias ocupaciones prehispánicas presentan materiales cerámicos, estructuras y características espaciales parecidas a las de Yánimas 1 (grandes espacios públicos rodeados de hábitats residenciales, montículos ceremoniales, etc.). Por ejemplo, en un análisis de restos óseos procedentes de una excavación efectuada en el montículo-plataforma principal del sitio La Rinconada, se ha identificado una menor diversidad de taxa que la reconocida para Yánimas 1, correspondiente exclusivamente a aves y mamíferos, entre estos últimos se destacan los restos de camélidos (Fernández Varela y Peña, 2004: 155).

Ahora bien, consideramos que al explorar el aprovechamiento de la fauna desde el punto de vista económico, solo se obtiene una aproximación parcial de la realidad. Pensamos que otros aspectos (simbólicos, religiosos, medicinales, etc.), pudieron estar involucrados durante las interacciones fauna/grupo humano. ¿Qué nos dicen los restos y el contexto excavado en el montículo EM1 con respecto a estos aspectos? En primer lugar, se sabe que tanto la llama como el taruca han sido animales venerados por comunidades prehispánicas de las tierras altas y utilizados en diversas prácticas rituales, como curaciones, ritos de fundación, entre otros. Tal vez, también lo hayan sido para grupos que habitaron las tierras bajas del NOA, al menos en el piedemonte tucumano. En tal sentido en el montículo más elevado del sitio Yánimas 1 (EM1), que presenta características particulares en el registro sedimentario y de algunos materiales culturales (que lo diferencian en parte de otros contextos relevados), se han registrado varias asociaciones de vestigios que incluyen partes del esqueleto de estos artiodáctilos, e incluso extremidades articuladas como en el caso del taruca. Otros animales que tal vez fueron venerados en tiempos prehispánicos, como es el caso de la vizcacha (Loza, 2007), también se registra en este montículo. Teniendo en cuenta la posible importancia simbólica que pudieron haber tenido estos animales (y otros como ñandúes, batracios y ofidios), tal vez su presencia en este montículo haya estado relacionada con otras actitudes y acciones que van más allá de la subsistencia. Inferimos, por ejemplo, que en este montículo pudo haberse dado la depositación de ofrendas que incluían conjuntos de varios elementos (orgánicos e inorgánicos) cuyos atributos y poderes especiales atribuidos por la comunidad habrían servido para cumplir con diversos fines rituales. 
Otros restos faunísticos que aportan (y complejizan) a esta cuestión son el silbato y el bezoar. El caso del silbato puede que sea bien ilustrativo de las ideas que estamos planteando. Según fuentes etnográficas, este objeto representa un elemento de poder y ha sido utilizado solo por chamanes en prácticas rituales tales como sesiones terapéuticas, desinfección ambiental y, además, como medio para lograr el vuelo espiritual o transformación chamánica (Califano, 1975; Metraux, 1944; Pérez Bugallo, 1989). Teniendo en cuenta esto, consideramos que la elección de la materia prima (hueso de ave rapaz) no debió ser arbitraria. Por el contrario, nos habla de una estrecha relación simbólica de ciertas personas (chamanes) con determinadas aves buenas voladoras cuyos huesos no solo son apropiados (desde el punto de vista físico y formal) para confeccionar estos silbatos, sino que además tendrían la capacidad de propiciar el vuelo del alma del chamán a partir de su uso (soplido). Estas prácticas chamánicas se llevaron a cabo bajo el efecto de sustancias psicotrópicas, como el polvo elaborado con las semillas del cebil (Anadenanthera colubrina var. cebil) (Califano, 1975; Metraux, 1944; entre otros). Cabe recordar aquí que en EM1 se encontraron cuatro tubos de pipas, dos de ellos cercanos al aerófono. El análisis microscópico de los residuos carbonosos adheridos al interior de estos tubos, permitió registrar microfósiles de plantas con propiedades sicotrópicas, como el cebil, evidencia que sugiere su consumo en prácticas fumatorias (Martin Silva et al., 2013). Entonces, este contexto nos sugiere el desarrollo de prácticas rituales que habrían permitido a ciertos agentes con poderes especiales y prestigio dentro de la comunidad (chamanes), conectarse con el mundo espiritual (los antepasados, las entidades del bosque) para diversos fines, mediante vuelos extáticos realizados a partir del uso de silbatos de hueso y estimulados por el consumo de enteógenos.

Otro elemento de origen animal presente en EM1 que pudo haber tenido un importante valor simbólico-religioso es el bezoar. Es posible que este tipo de objetos también hayan sido utilizados por ciertas personas con poderes especiales, como el de curar. En tal sentido, destacamos el hallazgo de una piedra bezoar o karwa jayintilla (en quechua) en un atado de cuero con varios objetos rituales y preparados medicinales, encontrado en un abrigo rocoso del cerro Pallqa (Amaguaya, departamento La Paz, región Circum-Titicaca) (Loza, 2007: 325, 328, 332). Resulta interesante que la autora considera que este envoltorio habría sido propiedad de un agente médico/religioso del período Tiwanaku (Horizonte Medio, 400-1100 d.C.), cuyo desarrollo ha sido en parte coetáneo con la ocupación de Yánimas 1.

Por otra parte, no podemos dejar de mencionar la presencia de especímenes termoalterados (quemados, carbonizados y hasta calcinados) en el registro arqueofaunístico, que se manifiesta fundamentalmente en restos de camélidos, roedores, quirquinchos y rheidos. Si bien la proporción de restos termoalterados en relación al total de la muestra es escasa, su presencia nos permite plantear algunas alternativas para explicar su representación en este registro. Por un lado, estas y otras huellas de origen antrópico podría estar indicando el consumo de estos animales tal vez como parte de banquetes compartidos por los miembros de la comunidad, en ceremonias y festividades 
que los reunían en determinadas ocasiones, y que posiblemente hayan tenido lugar en el espacio plano central delimitado por las elevaciones monticulares. Los restos de estas comidas de alto valor socio-simbólico, se habrían depositado finalmente en EM1. Por otro lado, la presencia de concentraciones de cenizas y carbones de diferentes tamaños a lo largo de casi toda la estratigrafía, y en varios casos vinculados a las asociaciones de restos que incluyen vestigios faunísticos termoalterados, también podría estar indicando que se trata de residuos de prácticas rituales relacionados con la quema de ofrendas compuestas por varios tipos de materiales. Estas prácticas son muy comunes en el ámbito andino y áreas cercanas (Gómez Cardozo et al., 2007). Estas quemas pudieron haberse desarrollado in situ, en el montículo, o bien en otros lugares, y luego los residuos de objetos y las cenizas (con significativas cargas simbólicas) fueron recogidos y finalmente depositados en EM1. Varias de estas actividades pudieron haber contribuido a la formación de este montículo.

Así, las evidencias expuestas en este trabajo contribuyen a reforzar la hipótesis ya propuesta en otros trabajos (Miguez et al., 2012; Miguez et al., 2013) sobre que el montículo EM1 representó un lugar con alto valor simbólico/religioso en este paisaje social, y que su construcción se habría desarrollado mediante la depositación de objetos y/o conjuntos de materiales y sedimentos en determinados eventos (no cotidianos), posiblemente vinculados a actividades rituales dirigidas por agentes con cierto poder simbólico-religioso (chamanes), que permitieron construir y mantener este espacio, que ha preservado la memoria, identidad y cosmovisión de los habitantes de Yánimas 1.

Si bien es cierto que en la cosmovisión de las comunidades prehispánicas del NOA, particularmente aquellas correspondientes al primer milenio d.C., lo sagrado puede estar presente en diversas prácticas, materiales y espacios de la vida cotidiana (Salazar et al., 2011), no es menos correcto pensar que la sacralidad y todo el simbolismo que la caracteriza se manifieste con mayor énfasis en determinados momentos y lugares, especialmente seleccionados por la comunidad para tal fin. Este parece ser el caso del montículo EM1 de Yánimas 1. Por último, consideramos que el enfoque de este trabajo ha permitido reunir un cúmulo de evidencias que posibilitan plantear una estrecha y compleja relación entre la fauna y los habitantes de este sitio, donde se entrelazan diversas percepciones y prácticas en las que los animales habrían tenido significativa participación.

\section{Agradecimientos}

Los autores agradecen el apoyo de las instituciones que financian sus investigaciones, como el Consejo de Investigadores de la Universidad Nacional de Tucumán (Beca de posgrado y Proyectos CIUNT 26/G449 y 26/G425). Se agradece a los Doctores Virginia Abdala, Ricardo Montero, Pablo Ortíz, Marco Mirandes, Gastón Aguilera y Sara Bertelli por su contribución en la identificación de algunos especímenes. 


\section{Bibliografía}

Adaro, L. y A. Benavente. 1990. "Identificación de patrones óseos de camélidos sudamericanos". En: Avances en Ciencias Veterinarias, Vol. 5, № 2, Santiago, Universidad de Chile, pp. 79-86.

Afanador Llach, M. J. 2011. "Nombrar y representar: escritura y naturaleza en el Códice de la Cruz-Badiano 1552". En: Revista de la Historia Colonial Latinoamericana, Vol. 16, $\mathrm{N}^{\circ}$ 1, Bogotá, Instituto Colombiano de Antropología e Historia, pp. 1341.

Apolinaire, E. y Turnes, L. 2010. “Diferenciación específica de Rheidos a partir de fragmentos de cáscaras de huevo. Su aplicación en sitios arqueológicos del Holoceno tardío". En: Berón, M.; Luna, L.; Bonomo, M.; Montalvo, C.; Aranda, C. y Carrera Aizpitarte, M. (ed) Mamül Mapu: pasado y presente desde la arqueología pampeana, Buenos Aires, Editorial Libros del Espinillo, pp. 253-260

Arenas, P. 2003. Etnografía y alimentación entre los toba-ñachilamole\#tek y wichilhuku'tas del Chaco Central (Argentina). Buenos Aires, Edición del autor.

Bárquez, R., Mares, M. y Ojeda, R. 1991. Mamíferos de Tucumán. Oklahoma (U.S.A.), University of Oklahoma.

Binford, L. 1981. Bones: Ancient Mens and Modern Myths. New York, Academic Press. Beherensmeyer, A. 1978. "Taphonomic and ecologic information from bone wathering". En: Paleobiology, $\mathrm{N}^{\circ}$ 4, Washington D.C., The Paleontological Society, pp. 150162.

Browman, D. L. 2004. "Tierras comestibles de la Cuenca del Titicaca: Geofagia en la prehistoria boliviana”. En: Estudios Atacameños, No 28, San Pedro de Atacama, Instituto de Investigaciones Arqueológicas y Museo R. P. G. Le Paige, Universidad Católica del Norte, pp. 133-141.

Brown, A. y Malizia, L. 2004. "Las Selvas Pedemontanas de las Yungas. En el umbral de la extinción". En: Ciencia Hoy, № 14, Buenos Aires, Asociación Civil Ciencia Hoy, pp. 52-63.

Califano, M. 1975. “El chamanismo mataco". Scripta Ethnologica, Vol. 3, N², Buenos Aires, Centro Argentino de Etnología Americana (CONICET). pp. 7-60.

Califano, M. y Dasso, M. C. 1999. El chamán wichí. Buenos Aires, Ciudad Argentina.

Caria, M.; Gómez Augier, J.; Cruz, H. y Zapatiel, J. 2011. “Aportes a la construcción de la variabilidad material de un sitio arqueológico en el piedemonte oriental de la Cumbres Calchaquíes - Tucumán”. En: Comechingonia, $\mathrm{N}^{\circ} 14$, Córdoba, Centro de Estudios Históricos Prof. Carlos S. A. Segreti, pp. 133-154.

Cartajena Fasting, I. 2009. "Explorando la variabilidad morfométrica del conjunto de camélidos pequeños durante el Arcaico Tardío y el Formativo Temprano en Quebrada Tulán, norte de Chile". En: Revista del Museo de Antropología, № 2 , Córdoba, Facultad de Filosofía y Humanidades (UNC), pp. 199-212.

Cione, A., Lorandi, A. M. y Tonni, E. 1979. "Patrón de subsistencia y adaptación ecológica en la aldea prehispánica El Veinte, Santiago del Estero". En: Relaciones, $\mathrm{N}^{\circ}$ 13, Buenos Aires, Sociedad Argentina de Antropología, pp. 103-116. 
Cruz, P. 2006. "Complejidad y heterogeneidad en los Andes meridionales durante el Período de Integración Regional (IV-X d.C.)". En: Bulletin de l'Institut Francais d'Études Andines, Vol. 35, N² 2, Lima, Instituto Francés de Estudios Andinos, pp. 121-148.

Dasso, M. C. 2008. "Notas sobre la alimentación wichí". En: Archivos, Vol. 6, Buenos Aires, Centro de Investigaciones en Antropología Filosófica y Cultural (CONICET), pp. 29-58.

Del Papa, L. 2010. "Revisión de la determinación de los materiales arqueofaunísticos provenientes del sitio Villa La Punta, Santiago del Estero". En: La Zaranda de Ideas, $\mathrm{N}^{\circ}$ 6, Buenos Aires, Sociedad Argentina de Antropología, pp. 25-36.

Descola, P. 2001. "Construyendo Naturalezas. Ecología simbólica y práctica social". En: Phillippe Descola y Gísli Pálsson (ed) Naturaleza y Sociedad. Perspectivas Antropológicas, Buenos Aires, Siglo Veintiuno Editores, pp. 101-123.

Díaz, N. I. 1995. "Antecedentes sobre la historia natural de la taruca (Hippocamelus antisensis D'Orbigny 1834) y su rol en la economía andina”. En: Chúngara, $\mathrm{N}^{\circ}$ 27, Arica, Universidad de Tarapacá, Chile, pp. 45-55.

Elkin, D. y Rosenfeld, S. 2001.”Análisis faunístico de Pintoscayoc 1 (Jujuy)”. En: Guillermo Mengoni Goñalons, Daniel Olivera y Hugo Yacobaccio (ed) El uso de los camélidos a través del tiempo, Buenos Aires, Ediciones del Tridente, pp. 29-64.

Escosteguy, P.; Salemme, M. y González, M. I. 2012. "Myocastor coypus ("coipo", Rodentia, Mammalia) como recurso en los humedales de la Pampa boanerense: patrones de explotación". En: Revista del Museo de Antropología, № 5, Córdoba, Facultad de Filosofía y Humanidades (UNC), pp. 13-30.

Fernández Varela, V. y Peña, J. 2004. "Análisis de restos arqueofaunísticos del sitio La Rinconada (Dpto. Ambato, Prov. de Catamarca)". En: Mariana Carballido Calatayud (ed) Mosaico. Trabajos en Antropología Social y Arqueología, Buenos Aires, Instituto Nacional de Antropología y Pensamiento Latinoamericano, pp. 153-161.

Franco Salvi, V. y Berberián, E. 2011. "Prácticas agrícolas de Sociedades Campesinas en el Valle de Tafí (100 a.C- 900 d.C)". En: Revista Chilena de Antropología, Vol. 24, N ${ }^{\circ}$ 2, Santiago, Universidad de Chile, pp. 119-145.

González, A. R. 1977. Arte precolombino de la Argentina. Buenos Aires, Filmediciones Valero.

González, A. R. 1998. Cultura de la Aguada. Arqueología y diseños. Buenos Aires, Filmediciones Valero.

Gómez Augier, J. y Caria, M. 2009. "Simbología prehispánica e histórica del Noroeste argentino y su relación con los cambios paleoambientales". En: Anales del Museo de América, $\mathrm{N}^{\circ}$ 17, Madrid, Museo de América, pp. 96-105.

Gómez Cardozo, C.; Chocobar, M. F. y Piñero, C. 2007. "El montículo de Casas Viejas: un espacio sagrado". En: Víctor Ataliva (ed) Paisajes y procesos sociales en Tafi. Una mirada interdisciplinaria desde el Valle (Tucumán, Argentina), San Miguel de Tucumán, Universidad Nacional de Tucumán, pp. 111-133. 
Gordillo, I. 2007. "Eran otros tiempos. Cronología de la Integración Regional en el NOA”. En: Verónica Williams; Beatriz Cremonte; Adriana Callegari y Hugo Yacobaccio (eds) Sociedades precolombinas Surandinas. Temporalidad, interacción y dinámica cultural del NOA en el ámbito de los Andes Centro-Sur. Buenos Aires, Taller Internacional de Arqueología del NOA y Andes Centro-Sur, pp. 221-234.

Gordillo, I. 2009. Dominios y recursos de la imagen. Iconografía cerámica del valle de Ambato. En: Estudios Atacameños, N 37, San Pedro de Atacama, Instituto de Investigaciones Arqueológicas y Museo R. P. G. Le Paige, Universidad Católica del Norte, pp. 99-121.

Gudemos, M. 2003. “¿Una danza de integración regional en las pinturas rupestres de La Salamanca?". En: Revista Española de Antropología Americana, № 33, Madrid, Universidad Complutense, pp. 83-119.

Izeta, A.; Otaola, C. y Gasco, A. 2009. "Estándares métricos y variabilidad de falanges proximales de camélidos sudamericanos. Su importancia como conjunto comparativo para interpretaciones en arqueología". En: Revista del Museo de Antropología, № 2, Córdoba, Facultad de Filosofía y Humanidades (UNC), pp. 169-180.

Kaufmann, C. 2009. Estructura de edad y sexo en guanaco. Estudios actualísticos y arqueológicos en Pampa y Patagonia. Sociedad Argentina de Antropología. Buenos Aires.

Kent, J. 1982. The domestication and explotation of the South American camelids: methods of analysis and their application of circum-lacustrine archaeological sites in Bolivia and Peru. Tesis Doctoral. St. Louis, Washington University, USA.

Korstanje, M. A. 1992. “Avances en el conocimiento del Formativo en el piedemonte oriental del Aconquija (SO de Tucumán)”. En: Cuadernos, N4, San Salvador de Jujuy, Facultad de Humanidades y Ciencias Sociales (UNJu), pp. 175-181.

Laguens, A. 2004. "Arqueología de la diferenciación social en el valle de Ambato, Catamarca, Argentina (s. II - VI d.C.): el actualismo como metodología de análisis". En: Relaciones, $N^{\circ} 29$, Buenos Aires, Sociedad Argentina de Antropología, pp. 137-161.

Lecoq, P. y Fidel, S. 2003. "Prendas simbólicas de camélidos y ritos agro-pastorales en el sur de Bolivia”. En: Textos Antropológicos, Vol. 14, N 1, La Paz, Universidad Mayor de San Andrés, pp. 7-54.

Llamazares, A. M. y Martínez Sarasola, C. 2004. "Reflejos de la cosmovisión originaria. Arte indígena y chamanismo en el Noroeste argentino prehispánico". En: Mateo Goretti (ed) Tesoros precolombinos. Buenos Aires, Fundación CEPPA, pp. 63-91.

López de Medina, C. 2012. "En compañía de los muertos. Ofrendas de animales en los cementerios de La Isla (Tilcara, Jujuy)". En: Intersecciones en Antropología, $\mathrm{N}^{\circ}$ 13, Olavarría, Facultad de Ciencias Sociales (UNCPBA), pp. 345-357.

Loza, C. B. 2007. "El atado de remedios de un religioso/médico del período Tiwanaku: miradas cruzadas y conexiones actuales". En: Bulletin de l'Institut Français d'Études Andines, $\mathrm{N}^{\circ}$ Vol. 36, $\mathrm{N}^{\circ}$ 3, Lima, Inst. Francés de Est. Andinos, pp. 317-342. 
Lyman, L. R. 1994. Vertebrate Taphonomy. Cambridge University Press, Cambridge.

Manasse, B. 1997. "La región pedemontana del Sudoeste de la Provincia de Tucumán.

Dptos. de Alberdi y La Cocha”. En: Shincal, $\mathrm{N}^{\circ}$ 6, Catamarca, Escuela de Arqueología (UNCa), pp. 141-152.

Martín Silva, V., Korstanje, M. A. y Miguez, G. 2013. “El uso prehispánico de enteógenos en selvas del Noroeste Argentino". En: Primer Simposio Internacional de Anadenanthera, Museo de Plantas Sagradas, Mágicas y Medicinales, Noviembre 5-9, 2013; Cusco, Perú, en prensa.

Mengoni Goñalons, G. 1988. "Análisis de los materiales faunísticos de sitios arqueológicos". En: Xama, $\mathrm{N}^{\circ}$ 1, Mendoza, Instituto de Ciencias Humanas, Sociales y Ambientales (CONICET), pp. 71-120.

Mengoni Goñalons, G. 1999. Cazadores de guanacos de la estepa patagónica. Colección tesis Doctorales, Sociedad Argentina Antropología. Buenos Aires. pp. 281.

Metraux, A. 1944. "Estudios de etnografía chaquense". En: Anales del Instituto de Etnología Americana, Vol. V, Mendoza, Universidad Nacional de Cuyo, pp. 263311.

Miguez, G. 2010. “Paisaje y espacialidades del sitio Yánimas 1 (provincia de Tucumán)”. En: XVII Congreso Nacional de Arqueología Argentina. Universidad Nacional de Cuyo, Octubre 11-15, 2010; Mendoza, Argentina, pp. 449-454.

Miguez, G. 2014. "Brillan en la selva: contexto y análisis técnico de objetos de oro hallados en un sitio prehispánico del piedemonte tucumano". En: Relaciones, Vol. 39, $\mathrm{N}^{\circ}$ 1, Buenos Aires, Sociedad Argentina de Antropología. pp, 277-284.

Miguez, G. y Collantes, M. 2012. "Geoarqueología de un sector del Piedemonte Meridional Tucumano”. En: V Congreso Argentino de Geomorfología y Geología del Cuaternario. Universidad Nacional de Río Cuarto, Octubre 2-5, 2012; Río Cuarto, Argentina, pp. 71-81.

Miguez, G.; Cuenya, P. y Caria, M. 2012. “Observaciones arqueopedológicas vinculadas a una ocupación prehispánica registrada en el sitio Yánimas 1 (Tucumán)". En: V Congreso Argentino de Geomorfología y Geología del Cuaternario. Universidad Nacional de Río Cuarto, Octubre 2-5, 2012; Río Cuarto, Argentina, pp. 61-70.

Miguez, G.; Nasif, N.; Gudemos, M. y Bertelli, S. 2013. “Aves, sonidos y chamanes.

Estudio interdisciplinario de un instrumento musical óseo procedente de una ocupación prehispánica de las selvas meridionales del noroeste de Argentina". En: Anales del Museo de América, ํ2 21, Madrid, Museo de América, En prensa. Miller, G. 1977. "Sacrificio y beneficio de camélidos en el sur de Perú". En: Jorge Flores Ochoa (ed) Pastores de Puna, Lima, Inst. de Estudios Peruanos, pp. 193-210.

Montero, R.; Abdala, V.; Moro, S y Gallardo, G. 2004. “Atlas de Tupinambis rufescens (Squamata: Teiidae). Anatomía externa, osteología y bibliografía”. En: Cuadernos de Herpetología, Vol. 18, N 1, Buenos Aires, Asociación Erpetológica Argentina (CAICYT-CONICET), pp. 17-32.

Morrone, J. 2002. "Presentación sintética de un nuevo esquema biogeográfico de América Latina y el Caribe”. En: C. Costa, S. Vanin, J. Lobo y A. Melic (ed) Proyecto de Red Iberoamericana de Biogeografía y Entomología Sistemática, PrIBES 2002, Zaragoza Monografías Tercer Milenio, Vol. 2, SEA, pp. 267-275. 
Nasif, N. y Gómez Cardozo, C.. 2007. "The archaeofauna of the El Pichao site (Sector III, Units 1 and 2), Tucumán province, Northwestern Argentina”. En: María Gutiérrez, Laura Miotti, Gustavo Barrientos, Guillermo Mengoni Goñalons y Mónica Salemme (ed) Taphonomy and Zooarchaeology in Argentina, Oxford, B.A.R. I. Series, pp. 35-45.

Nasif, N.; Corbalán, M.; Moreno, A. y Gavícola, M. 2007. "La explotación de recursos faunísticos en el sitio Mortero Hachado (Departamento Trancas, Tucumán”. XVI Congreso Nacional de Arqueología Argentina. Universidad Nacional de Jujuy, Octubre 8-12, 2007; Jujuy, Argentina. Tomo III, pp. 179-185.

Olrog, C. 1995. Las Aves Argentinas. Buenos Aires, El Ateneo.

Olrog, C. y Lucero, M. 1981. Guía de los Mamíferos Argentinos. San Miguel de Tucumán, Fundación Miguel Lillo.

Ortíz, P.; Jayat, P.; Nasif, N.; Teta, P. y Haber, A. 2012. "Roedores del Holoceno tardío de la Puna de Atacama, sitio arqueológico Tebenquiche Chico, Catamarca, Argentina". En: Archaeofauna, $\mathrm{N}^{\circ}$ 21, Madrid, Universidad Autónoma de Madrid, pp. 249-266.

Ottalagano, F. 2007. "Algunas referencias en torno al simbolismo de las aves en los registros etnohistóricos y etnográficos de guaycurúes y mataco-mataguayos”. En: Arqueología Suramericana, Vol. 3, N², Popayán, Universidad de Cauca (Colombia), pp. 213-228.

Pacheco Torres, V.; Altamirano Enciso, A. y Guerra Porras, E. 1986. "The Osteology of South American Camelids". En: Archaeological Research Tools, № 3, Los Angeles, Institute of Archaeology, University of California. pp. 32.

Pérez Bugallo, R. 1989. "Los silbatos chaquenses". En: Relaciones, Vol. 17, ํ 2 , Buenos Aires, Sociedad Argentina de Antropología, pp. 87-97.

Pérez Miranda, C. 2003. Tucumán y los recursos naturales. Buenos Aires, Bifronte.

Puig, S. y Monge, S. 1983. Determinación de la edad en Lama guanicoe (Müller). En: Deserta, $\mathrm{N}^{\circ}$ 7, Mendoza, Instituto Argentino de Investigaciones de las Zonas Áridas (IADIZA-CONICET), Gobierno de Mendoza - Universidad Nacional de Cuyo, pp. 246-270.

Quintana, C. y Mazzanti, D. 2011. "Las vizcachas pampeanas (Lagostomus maximus, Rodentia) en la subsistencia indígena del Holoceno tardío de las sierras de Tandilia oriental (Argentina)". En: Latin American Antiquity, $\mathrm{N}^{\circ} 22$, Washington D.C., Society for American Archaeology, pp. 253-270.

Rendace, S.; Argañaraz Fochi, D.; Cordomí, A. y Cuenya, P. 2006. "Pedología y niveles de ocupación arqueológica”. En: III Congreso Argentino de Cuaternario y Geomorfología. Universidad Nacional de Córdoba, Octubre 11-13, 2006; Córdoba, Argentina, pp. 827-836.

Salazar, J.; Franco Salvi, V. y Berberián, E. 2011. "Una aproximación a la sacralidad de los espacios domésticos del primer milenio en el Valle de Tafí (Noroeste Argentino)". En: Revista Española de Antropología Americana, Vol. 41, $\mathrm{N}^{\circ}$ 1, Madrid, Universidad Complutense, pp. 9-26. 
Salemme, M.; Escosteguy, P. y Frontini, R. 2012. "La fauna de porte menor en sitios arqueológicos de la región pampeana, Argentina. Agente disturbador vs. recurso económico". En: Archaeofauna, $\mathrm{N}^{\circ}$ 21, Madrid, Univ. Autónoma de Madrid, pp. 163-185.

Sesma, P.; Guido, E. y Puchulu, M. E. 1998. "Clima de la Provincia de Tucumán". En: Gianfrancisco, M.; Puchulu, M. E.; Durango de Cabrera, M. y Aceñolaza, F. (ed) Geología de Tucumán, San Miguel de Tucumán, Colegio de Graduados en Ciencias Geológicas de Tucumán, pp. 41-46.

Santini, M. 2011. "Aprovechamiento de Myocastor coypus (Rodentia, Caviomorpha) en sitios del Chaco Húmedo argentino durante el Holoceno tardío". En: Intersecciones en Antropología, $\mathrm{N}^{\circ} 12$, Olavarría, Facultad de Ciencias Sociales (UNCPBA), pp. 195-205.

Santori, J. y Colasurdo, M. B. 2012. "La recurrencia del coipo (Myocastor coypus) en los registros arqueofaunísticos de la cuenca inferior del río Paraná (Argentina)". En: Arqueología Iberoamericana, $\mathrm{N}^{\circ} 13$, España. pp. 23-36.

Scattolin, M. C. y Korstanje, M. A. 1994. "Tránsito y frontera en los Nevados del Aconquija". En: Arqueología, $\mathrm{N}^{\circ}$ 4, Buenos Aires, Instituto de Arqueología (UBA), pp. 165-197.

Suárez, M. E. 2012. "Espíritus vinculados con el bosque y sus plantas en el mundo de los wichís de Chaco Semiárido salteño". En: Pastor Arenas (ed) Etnobotánica en zonas áridas y semiáridas del Cono Sur de Sudamérica, Buenos Aires, Consejo Nacional de Investigaciones Científicas y Técnicas, pp. 145-177.

Tartusi, M. y Nuñez Regueiro, V. 2003. "Procesos de interacción entre poblaciones de los valles intermontanos del noroeste argentino y las del piedemonte". En: Anales Nueva Época, $\mathrm{N}^{\circ}$ 6, Goteborg, Instituto Ibero Americano, pp. 43-62.

Vuotto, L. 1999. "Recolección animal entre los Tobas de Formosa". En: Carlos Aschero, M. Alejandra Korstanje y Patricia Vuotto (ed) En los tres reinos: prácticas de recolección en el Cono Sur de América, San Miguel de Tucumán, Instituto de Arqueología y Museo (UNT), pp. 253-260. 